\title{
El derecho humano al agua como mínimo vital en Andalucía
}

\author{
Lorenzo Mellado Ruiz
}

Profesor Titular de Derecho Administrativo

Universidad de Almería

SUMARIO. I. INTRODUCGIÓN; II.CARACTERIZACIÓN FORMAL Y MATERIAL DEL DERECHO AL AGUA; 1. El derecho al agua como derecho humano fundamental; A. Reconocimiento internacional; B. Regulación comunitaria: de la Directiva Marco a la Propuesta de Directiva relativa a la calidad de las aguas destinadas al consumo humano; C. Proyección y construcciones dogmáticas a nivel interno: el derecho al agua como expresión de la garantía constitucional a un "mínimo existencial"; D. Síntesis y propuestas: el agua como bien común y su acceso como mínimo vital; 2. Aproximación al contenido y objeto del derecho al agua; III. ANÁLISIS ESPECÍFICO DE LA INTRODUCGIÓN DE LA CLÁUSULA VITAL AL AGUA EN LA LEGISLACIÓN ANDALUZA DE AGUAS; 1. Contextualización inicial: la integración entre las políticas hídricas y la respuesta frente al cambio climático; 2. ¿Es competente la Comunidad andaluza para proclamar este derecho?; 3. Elementos; A. Marco axiológico; a). Funcionalidad de los principios de utilización solidaria del agua, de igualdad de trato y de protección de la salud de los usuarios; b). El uso racional del agua como obligación básica de la Administración; B. Contenido; a). Accesibilidad universal; b). Carácter domiciliario; c). Disponibilidad y unicidad económica; d). Objeto: volumen de agua apta para el consumo humano; e). Fin: atender las necesidades básicas y el saneamiento; C. Sujetos; 4. Ejercicio del derecho: ¿transformación o realismo jurídico?; 5. Derecho al agua y "pobreza hídrica"; IV. FINAL

RESUMEN: Se analiza en este estudio la reciente introducción en el derecho regional andaluz del derecho al agua como mínimo vital. Se parte, para ello, de la caracterización formal y material del ya conocido derecho al agua, en sus diferentes niveles territoriales, desde la premisa básica de su articulación como garantía constitucional a un mínimo existencial. El análisis fundamental se centra en el estudio de los diversos elementos de la nueva D. A. 16 a de la Ley andaluza de Aguas. Se revisan,

Recibido: 19/03/2019

Aceptado: 05/06/2019 
así, los principios inspiradores de esta nueva previsión, su contenido y características, fines, etc., desde una reflexión crítica sobre el efectivo alcance de las previsiones legales, dada su conexión inmediata, en el fondo, con el grupo normativo relativo a la prestación de los servicios del agua en el nivel local de gobierno. Y se acaba con unas consideraciones específicas de las relaciones entre esta cláusula del derecho al agua y las nuevas situaciones de pobreza hídrica.

PALABRAS CLAVE :Derecho al agua, mínimo vital, uso racional del agua, accesibilidad universal y disponibilidad del recurso, pobreza hídrica.

ABSTRACT: In this study, the recent introduction of the right to water as a vital minimum into regional Andalusian law is analyzed. We start, for this, the formal and material characterization of the already known right to water, in its different territorial levels, from the basic premise of its articulation as a constitutional guarantee to an existential minimum. The basic analysis focuses on the study of the various elements of the new D. A. 16th of the Andalusian Water Law. The inspiring principles of this new forecast, its content and characteristics, aims, etc., are reviewed from a critical reflection on the effective scope of the legal provisions, given its immediate connection, in the background, with the relative regulatory group to the provision of water services at the local level of government. And it ends with some specific considerations of the relationships between this clause of the right to water and new situations of water poverty.

KEY WORDS : Right to water, vital mínimum, rational use of water, universal accessibility and resource availability, water poverty.

\section{INTRODUCGIÓN}

La Disposición Final $4^{\text {a }}$ de la reciente Ley 8/2018, de 8 de octubre, de medidas frente al cambio climático y para la transición hacia un nuevo modelo energético en Andalucía ${ }^{1}$, ha venido a introducir en el subordenamiento jurídico sectorial sobre

\footnotetext{
1 «Disposición adicional decimosexta. Derecho humano al agua como mínimo vital. Los principios de utilización solidaria del agua, de igualdad de trato y de protección de la salud de los usuarios contemplados en el artículo 5 de esta ley, unidos a la finalidad de atender las necesidades básicas de consumo doméstico a un precio asequible a la que se refiere el artículo 111 bis.2 del Texto Refundido de la Ley de Aguas, amparan la garantía y protección del derecho humano al agua entendido como el acceso universal, de carácter domiciliario y a un precio accesible y unitario, de un volumen de agua apta para el consumo humano para atender las necesidades básicas, así como al saneamiento. Las condiciones de prestación y acceso al derecho humano al agua, concebido como mínimo vital, serán objeto de desarrollo reglamentario en la disposición administrativa de carácter general que contemple las relaciones entre las entidades que prestan los distintos servicios que componen el ciclo integral del agua de uso urbano y los usuarios de los mismos. Las personas en situación de pobreza y riesgo de exclusión social que acrediten dicha condición ante la Administración responsable de la gestión de los servicios del ciclo integral podrán ser objeto de bonificación
} 
aguas, aun ancilarmente, una previsión relativamente importante, desde el punto de vista de la forma y términos de su recepción legal, pero trascendental, desde la perspectiva de su funcionalidad material, como es la consagración legal expresa del derecho humano al agua como mínimo vital. Se ha añadido así una nueva Disposición Adicional $16^{a}$ a la Ley 9/2010, de 30 de julio, de Aguas de Andalucía, reconociendo, con ciertos matices, este derecho humano, de amplia implantación y reconocimiento a nivel internacional, pero huérfano de una articulación específica, uniforme y, sobre todo, material, a nivel interno.

Puede resultar interesante, pues, contrastar la progresiva conformación, contenido y operatividad concretas del mismo con la introducción expresa de su reconocimiento en la Ley de Aguas andaluza, desde la premisa fundamental de partida de que, lógicamente, no se trata de una nueva, o primera, "regulación" del derecho al agua en nuestra Comunidad Autónoma, incluyendo su contenido y, sobre todo, el conjunto de facultades inherentes o derivadas del mismo, sino un reconocimiento formal, ciertamente ambiguo en cuanto a sus términos, necesitado necesariamente de un futuro y completo desarrollo reglamentario. Además, y superando los planteamientos y limitaciones programáticas de los reconocimientos internacionales, nos encontramos pendientes de la aprobación de la nueva Directiva general sobre calidad de las aguas destinadas al consumo humano, norma de obligado cumplimiento e implementación que ha de incidir lógicamente en la interpretación y desarrollo de las plasmaciones específicas de este derecho a nivel interno.

No obstante, resulta loable esta nueva previsión, sino novedosa, sí en la línea de la legislación sectorial autonómica más moderna, superando los enfoques -fruto de la denominada "guerra del agua"- ya conocidos del mismo relativos a la dimensión territorial del derecho al agua, su incidencia clave en el sistema de distribución competencial sobre el recurso y la propia conflictividad autonómica derivada fundamentalmente de algunos de los Estatutos de Autonomía de nueva generación, donde el agua (o el Guadalquivir, en el caso de Andalucía) se convirtieron en auténticos "símbolos" del autogobierno.

Se ha dado, ahora, un paso más. Aunque no se trate de una auténtica y plena "sustantivización" operativa del derecho, es decir su configuración material necesaria como derecho subjetivo, efectivamente exigible, sí se ha producido, en línea con la progresiva decantación del mismo en el orden internacional, su reconocimiento legal expreso, base de cualquier -y deseable- desarrollo ulterior, en un contexto ancilar, por lo demás, adecuado y lógico: la inevitable incidencia del cambio climático, como objeto nuclear de la nueva Ley, sobre los recursos hídricos de nuestro planeta.

al suministro mínimo vital de agua y al saneamiento básico en los términos que reglamentariamente se determinen.» 
Se analizan en este estudio, así, las características fundamentales de este reconocimiento autonómico, en contraste con su progresiva configuración a nivel internacional, comunitario e interno y en el contexto de las medidas articuladas por esta nueva Ley para luchar contra el cambio climático.

\section{CARACTERIZACIÓN FORMAL Y MATERIAL DEL DERECHO AL AGUA}

\section{El derecho al agua como derecho humano fundamental}

\section{A. Reconocimiento internacional}

Como se sabe, a falta de reconocimiento explícito², el derecho humano al agua ha sido deducido de las referencias de la Declaración de derechos humanos de 10 de diciembre de 1948 y del Pacto Internacional de Derechos Económicos, Sociales y Culturales de 1966 a los derechos nucleares relativos a la protección de la salud, a la alimentación y a la vivienda. Ha sido definido así como "el derecho de todos a disponer de agua suficiente, salubre, aceptable, accesible y asequible para el uso personal y doméstico"3. La falta de calificación específica, al tratarse de una definición centrada más en el contenido y características del derecho que en su propia naturaleza, sería subsanada más adelante a través de la importante Resolución 64/292, de 28 de julio de 2010, de la Asamblea General, reconociéndose el derecho al agua potable y al saneamiento como "derecho humano esencial" para el pleno disfrute de la vida y de todos los derechos humanos.

Desde este capital pronunciamiento el derecho humano al agua ha sufrido una progresiva expansión y densificación ${ }^{4}$, sobre la base de dos ejes fundamentales: la singularidad, por la escasez, irregularidad y fragilidad ecosistémica del recurso, y la radicalidad, por constituir un elemento vital y presupuesto por tanto del ejercicio del resto de derechos del hombre.

Sin agua no hay vida. Hay organismos que pueden vivir sin oxígeno, pero no sin agua. Es pues, desde el punto de vista de la propia existencia, el recurso natural más importante que existe. Es lógico, por ello, que se haya planteado la necesaria

2 Vide CASTILLO DAUDÍ, M., "El derecho humano al agua en el Derecho internacional: aspectos generales", en A. EMBID IRUJO (coord.), El derecho al agua, Thomson Aranzadi, Pamplona, 2006, p. 57 y ss.

3 Comité de Derechos Económicos, Sociales y Culturales del Consejo Económico y Social de las Naciones Unidas, $29^{\mathrm{a}}$ período de sesiones, Ginebra, 11 a 29 de noviembre de 2002.

4 Vide. la evolución de tal reconocimiento en RODRÍGUEZ ÁLVAREZ, A., "El derecho al agua en el contexto internacional y en el ordenamiento jurídico interno español”, en Revista de Derecho, Agua y Sostenibilidad (REDAS), núm. 2 (2018). 
existencia de un derecho humano a un mínimo vital de agua, a una cantidad mínima que le permita la propia subsistencia, desarrollo y desenvolvimiento personal y social. Hoy, el objetivo núm. 6 de los Objetivos de Desarrollo Sostenible (ODS), pilares fundamentales de la nueva Agenda de la ONU 2030 sobre el Desarrollo Sostenible, establece, de forma ambiciosa, que es necesario garantizar para ese año la "disponibilidad y la gestión sostenible del agua y el saneamiento para todos".

Pero a partir de tal reconocimiento a nivel internacional ${ }^{5}$, el problema reside obviamente en su exigibilidad y garantía, tanto desde el punto de vista formal de su existencia autónoma y propia (incluyendo la vinculatoriedad, el despliegue de efectos jurídicos y su alegación ante los poderes públicos internos) como material de las características que deberían tener las prestaciones de agua potable susceptibles de exigencia (status jurídico) ${ }^{6}$. La especificidad y garantías prestacionales asociadas al despliegue del contenido material del derecho quedan diluidas lógicamente en la falta de contenido vinculante y de mecanismos de materialización propias de las grandes declaraciones internacionales de derechos ${ }^{7}$.

A pesar de la inexistencia de un reconocimiento originario explícito, quizás seguramente por su propia evidencia como auténtico "presupuesto humano vital", que puede aún hoy llevar a la discusión sobre el carácter autónomo o no de este derecho (desde su propia decantación -y entrecruzamiento optimizador- a partir de otros derechos humanos sí reconocidos positivamente), es evidente que, en el plano internacional, sí nos encontramos ante un auténtico derecho humano ${ }^{8}$, presupuesto, además, de la existencia y ejercicio de cualquier otro (como uno de los denominados

5 Por ejemplo, AGUIAR RIBEIRO DO NASCIMENTO, G., "El derecho al agua y su protección en el contexto de la Corte Interamericana de Derechos Humanos", en Estudios Constitucionales, núm. 1 (2018), p. 245 y ss.; TORTAJADA, C., "Water as a human right", en International fournal of Water Resources Development, Vol. 33, núm. 4, (2017), p. 509 y ss.; y sobre todo el estudio de CALVETE MORENO, A., El derecho humano al agua, en J. TORNOS MAS (coord.), El servicio de suministro de agua en España, Francia e Italia, Iustel, Madrid, 2018, p. 59 y ss.

6 Sobre esta cuestión central puede verse por ejemplo MITRE GUERRA, E. J., El derecho al agua. Naturaleza jurídica y protección legal en los ámbitos nacionales e internacional, Iustel, Madrid, 2012. Deficiencias que han sido puestas también de manifiesto en dicho ámbito internacional, como explica por ejemplo CAHILL, A., "The human right to water - a right of unique status: The legal status and normative content of the right to water", en International Journal of Water Resources Development, Vol. 9, núm. 3, (2006), p. 389 y ss.

7 Son interesantes en este sentido algunas propuestas doctrinales superadoras, en el ámbito de la alegación jurisdiccional del derecho, de la perspectiva tradicional individualista de acceso, a través de lo que se ha podido denominar "derechos subjetivos de acción popular", vide REGO BLANCO, M. D., La acción popular en el Derecho administrativo, y, en especial, en el urbanístico, Instituto Andaluz de Administración Pública, Sevilla, 2005, p. 128.

8 Así, por ejemplo, LOPERENA ROTA, D., "El agua como derecho humano", en S. GONZÁLEZ-VARAS IBÁÑEZ (coord.), Nuevo Derecho de aguas, Thomson-Civitas, Pamplona, 2007, p. 82. 
"derechos humanos emergentes"). Debería incluirse, pues, dentro de la categoría dogmática de los derechos humanos de primera generación, por su carácter intrínseco a la naturaleza, dignidad y existencia humanas -y previo a la institucionalización de las organizaciones sociales y políticas-. Y en este sentido, cobran hoy especial relevancia, aparte de las características materiales que debería reunir en su materialización efectiva (disponibilidad, accesibilidad, continuidad, calidad, etc.), las exigencias adicionales de igualdad, equidad y universalidad en el acceso, equilibrio territorial, no discriminación, inclusión social y garantía de un suministro mínimo vital y sostenibilidad efectiva del abastecimiento ${ }^{9}$. El tránsito de las grandes declaraciones internacionales y de los principios generales a las normas internas debería pivotar, en este caso concreto, en la definición (doméstica) del "contenido mínimo esencial" que debería tener el derecho al agua, como exigencia indisponible de un derecho humano primario ${ }^{10}$, y si dentro del mismo habría de incluirse ese acceso mínimo vital que constituye ahora en nuestra Comunidad Autónoma el auténtico presupuesto radical de su reconocimiento legal.

B. Regulación comunitaria: de la Directiva Marco a la Propuesta de Directiva relativa a la calidad de las aguas destinadas al consumo humano

Todos estos planteamientos han tenido recepción, lógicamente, a nivel comunitario, desde fundamentos competenciales indirectos pero esenciales, como es la dimensión ecológica de los recursos hídricos y su incidencia en las condiciones básicas vitales de los ciudadanos. Con la recepción europea de este derecho, más o menos explícita, se densifica lógicamente además su auténtica naturaleza dogmática, no

9 Como se ha dicho, el progresivo y expreso reconocimiento del derecho humano al agua, tanto a nivel internacional como interno, debería servir de "referente para la universalización del acceso y la protección ambiental de los recursos hídricos", MITRE GUERRA, E., "La protección del derecho al agua en el derecho constitucional comparado y su introducción en los criterios de tribunales internacionales de derechos humanos", en Pensamiento jurídico, núm. 35, (2012), p. 232.

10 Es evidente que no siendo un derecho específicamente positivizado no cabe alegar, en este sentido, la conocida reserva legal de protección frente a la degradación normativa de la regulación de las libertades y derechos fundamentales contenida en el art. 53.1 CE, pero sí cabría pensar en un "contenido positivo" de dicha garantía, en cuanto afirmación de una sustancia última, indisponible e ineluctable de dicho derecho, y de contenido inequívocamente "jurídico". Con independencia de su positivización o reconocimiento expresos, se trataría del "reducto último que compone la sustancia del derecho", PAREJO ALFONSO, L., "El contenido esencial de los derechos fundamentales en la jurisprudencia constitucional: a propósito de la Sentencia del Tribunal Constitucional de 8 de abril de 1981", en Revista Española de Derecho Constitucional, núm. 3, (1981), p. 180. Como se ha dicho, "el contenido esencial es más una figura retórica que dogmática de la protección de los derechos fundamentales", pero obliga, al menos, en relación a mi juicio con aquéllos no positivizados, a una efectiva ponderación regulatoria, LOTHAR, Michael, “¿El contenido esencial como común denominador de los derechos fundamentales en Europa?", en Revista de Derecho Constitucional Europeo, núm. 11, (2009). 
tanto como derecho subjetivo pleno, como veremos, sino como prestación efectivamente exigible frente a los poderes públicos competentes.

Efectivamente, aunque la Carta de los Derechos Fundamentales de la Unión Europea de 2000 sigue sin hacer referencia específica al derecho al agua (pero sí, obviamente, a los derechos interrelacionados a la salud y a la calidad de vida), la cercana Carta Europea de los recursos de agua, adoptada como Recomendación en 2001 por el Consejo de Ministros, sí declara literalmente que "toda persona tiene derecho a disponer de agua suficiente para satisfacer sus necesidades esenciales" ${ }^{\prime 1}$. La disponibilidad -individual y colectiva- de agua suficiente y su vinculación a la garantía de un mínimo vital existencial - de desarrollo y de necesidades personales- ha de correlacionarse, así, con una gestión sostenible, tanto cuantitativa como cualitativamente, del recurso, y su articulación reguladora y prestacional con la garantía de incolumidad de los ecosistemas acuáticos, el aseguramiento integrado de un alto nivel de protección y su inmediata conexión con la salud y bienestar humanos. La conocida Directiva marco del agua se fundamenta, así, en su dimensión fundamentalmente ecológica ${ }^{12}$. Como dice su propio Considerando $24^{\circ}$, una gestión eficiente y sostenible de los recursos (desde una óptica más cuantitativa) y la garantía de su buena calidad contribuirán a garantizar el abastecimiento de agua potable a la población ${ }^{13}$.

El siguiente paso hacia la construcción - o al menos el reconocimiento- del derecho de acceso y saneamiento al agua en el ámbito comunitario hay que buscarlo

11 El derecho de acceso a servicios básicos de calidad, incluido el acceso al agua, es, de hecho, uno de los principios fundamentales del denominado "pilar europeo de los derechos sociales", aprobado por los Jefes de Estado o de Gobierno en la Cumbre de Gotemburgo de 17 de noviembre de 2017, en https:// ec.europa.eu/commission/sites/beta-political/files/social-summit-european-pillar-social-rights-booklet en.pdf.

12 Directiva 2000/60/CE, del Parlamento Europeo y del Consejo, de 23 de octubre, por la que se establece un marco comunitario de actuación en el ámbito de la política de aguas. Sobre la misma y su desarrollo posterior pueden verse con el máximo aprovechamiento el conjunto de estudios contenido en J. AGUDO GONZÁLEZ, (coord.), El derecho de aguas en clave europea, La Ley, Madrid, 2010 y, del mismo autor, "La Directiva marco. La nueva cultura del agua y el imperativo de evolución de la política hidráulica española hacia un modelo de gestión sostenible", en S. GONZÁLEZ-VARAS IBÁÑEZ, Nuevo Derecho de aguas, Thomson-Civitas, Madrid, 2007, p. 131 y ss.

13 Es verdad que la Directiva marco no reconoce explícitamente - de hecho, sólo utiliza una vez la expresión "derecho"- el derecho al agua, lógicamente desde su limitada funcionalidad de aproximación y uniformización reguladoras de los derechos internos, de los propios límites sustantivos de incidencia normativa en la materia y de la priorización del principio de libertad doméstica institucional para la organización de los servicios públicos sobre el agua, presupuesto y base para la satisfacción indirecta de este derecho. No obstante, sí establece expresamente que su objeto es establecer un marco para la protección -no tanto, en este sentido, para la regulación- de las aguas superficiales continentales, las aguas de transición, las aguas costeras y las aguas subterráneas que contribuya, entre otros fines, a "garantizar el suministro suficiente de agua superficial o subterránea en buen estado, tal como requiere un uso del agua sostenible, equilibrado y equitativo". 
en la reciente Propuesta de Directiva relativa a la calidad de las aguas destinadas al consumo humano (Documento COM 2017, 753 final, de 1 de febrero de 2018). Fruto de la primera Iniciativa Ciudadana Europea "Right2Water" (con más de 1,8 millones de firmas), en la que se instaba a que "por obligación, las instituciones comunitarias y los Estados miembros velen porque todos los ciudadanos puedan ejercer el derecho al agua y el saneamiento", parte de la necesidad primaria de que todos los Estados garanticen, así, un suministro de agua mínimo para todos los ciudadanos ${ }^{14}$. Pretende asegurarse, como objetivo primordial, un acceso universal, equitativo y sostenible al agua potable, como garantía esencial mínima de prestación pública y justicia social (de ahí, por ejemplo, su mención a la garantía de disponibilidad y suficiencia por parte de grupos vulnerables y marginados).

En un marco superior de transición hacia nuevos modelos de economía circular ${ }^{15}$, en donde cabe incluir la gestión eficiente e integrada del agua potable, como garantía de su suministro, y de optimización del uso de la energía, evitando por ejemplo las pérdidas innecesarias del agua o su distribución irregular o inequitativa, en tiempo y en espacio, y de adicional afección lógica sobre su disponibilidad y calidad a causa del cambio climático ${ }^{16}$, la nueva Directiva pretende trascender el enfoque

14 A través de la Resolución de 8 de septiembre de 2015, el Parlamento Europeo aboga por la plena realización del derecho humano al agua, esencial para la vida y la adecuada gestión de los recursos hídricos, al desempeñar un papel crucial a la hora de garantizar el uso del agua y salvaguardar el capital natural del mundo, solicitando a la vez Comisión el efectivo reconocimiento del acceso universal al agua.

15 Vide, fundamentalmente, la Comunicación de la Comisión "Closing the loop: An EU action plan for the Circular Economy", Documento COM 2015/0614 final. Como se ha señalado desde las propias instituciones comunitarias, la economía circular implica dotar al crecimiento económico de inteligencia y sostenibilidad. El modelo lineal de crecimiento económico, basado en la hipótesis de la abundancia y el progreso - aún sostenido- no se ajusta claramente a las necesidades de la sociedad actual, en un mundo globalizado y reticular, ni a la propia capacidad de acogida y resistencia del ambiente. El modelo de economía circular persigue, así, mantener el valor añadido de los productos el mayor tiempo posible, minimizando o excluyendo la producción de residuos y optimizando al máximo su funcionalidad, directa o indirecta, por ejemplo, en el tema que nos ocupa, a través de medidas efectivas y eficientes de reutilización del agua. Vide. BELDA HÉRIZ, I., Economía circular. Un nuevo modelo de producción y consumo sostenible, Tébar, Madrid, 2018 y GARCÍA GARCÍA, S., "Economía circular: la Unión Europea impulsa reformas sobre la base de un tema crucial, la gestión de residuos, con el fin de alcanzar mejoras económicas y medioambientales", en Actualidad Jurídica Ambiental, núm. 57, (2016).

16 Por ejemplo, MONTORO CHINER, M. J., "Agua, Derecho y cambio climático", en Revista Aragonesa de Administración Pública, núm. Extra 11, (2009), p. 227. Es más que evidente a estas alturas que el cambio climático y el calentamiento global del Planeta están teniendo, y tendrán, importantes repercusiones sobre los recursos hídricos y en consecuencia sobre las políticas y decisiones públicas correspondientes, entre otros aspectos a los efectos de asegurar los usos comunes generales y las demandas locales de abastecimiento domiciliario. Como se viene repitiendo, los problemas fundamentales serían el agravamiento de la escasez e irregularidad del recurso, con merma consiguiente de la calidad de las reservas, y de la gravedad y reiteración de las inundaciones, aunque, como se ha destacado, el riesgo es esencialmente "global" y "sistémico". Se precisan, así, medidas de mitigación necesarias para gestionar el agua en tiempos de estrés hídrico, ya sea como consecuencia de inundaciones o de sequías. vide PAREJO ALFONSO, L., "Cambio 
sectorial clásico centrado en los mecanismos formales - y de trasfondo económico- de control cualitativo público del agua de uso humano hacia nuevos postulados de gestión integrada de los riesgos (sobre la calidad, el abastecimiento, la suficiencia, etc.) y transparencia y participación en la gestión del recurso. Aunque lógicamente, por el instrumento normativo utilizado y las limitaciones competenciales, la propuesta de Directiva viene a establecer normas generales a nivel comunitario, con respeto del principio general de subsidiariedad, sí se concede a los Estados miembros un margen de apreciación expreso para que decidan la forma de aplicar la obligación de mejorar el acceso a un agua potable segura. No hay, pues, un reconocimiento material expreso del derecho universal a un mínimo de agua potable, como derecho subjetivo ciudadano, pero sí una obligación pública específica de mejorar los niveles, sistemas, instrumentos y características del acceso al agua destinada al consumo humano. Se trataría de garantizar el respeto a este derecho humano a través de la protección de los servicios básicos de interés -económico- general relacionados con el mismo ${ }^{17}$. El art. 13 de la propuesta pone el acento, así, no tanto en la distribución, prestación o suministro, sino en el "acceso", que se traduciría en dos obligaciones fundamentales para los Estados miembros: i) la obligación de mejorar el acceso al agua potable y promover su uso a través de diferentes medidas (evaluar el porcentaje de personas sin acceso, fomentar el uso del agua del grifo en los edificios públicos y restaurantes, garantizar que en la mayoría de las ciudades se dispone de los equipos necesarios para acceder libremente al agua del grifo, etc.) y ii) la obligación de adoptar todas las medidas necesarias para garantizar el acceso al agua potable para los grupos vulnerables y marginados.

La conexión del derecho fundamental al agua - como trasunto o proyección de los derechos a la vida y a la salud- con la garantía de acceso equitativo supone trascender las visiones tanto cuantitativas (suficiencia) como cualitativas (calidad) de la gestión del recurso, poniendo el acento en la seguridad, universalidad y asequili-

\footnotetext{
climático, riesgo global, innovación y Derecho", en L. PAREJO ALFONSO (coord.), El Derecho ante la innovación y los riesgos derivados del cambio climático, Tirant lo Blanch, Valencia, 2006, p. 10. La actual Directiva 2007/60/CE, de 23 de octubre, de evaluación y gestión de los riesgos de inundación, parte precisamente de la constatación de que aunque las inundaciones son fenómenos naturales que en principio no pueden evitarse, "algunas actividades humanas (como el incremento de los asentamientos humanos y los bienes económicos en las llanuras aluviales y la reducción de la capacidad natural de retención de las aguas por el suelo) y el cambio climático están contribuyendo a aumentar las probabilidades de que ocurran, así como su impacto negativo". Para un primer análisis de la misma puede verse, por ejemplo, DELGADO PIQUERAS, F., "La irrupción del cambio climático en el Derecho europeo de aguas", en Revista Aragonesa de Administración Pública, núm. Extra 11, (2009), p. 276 y ss.

17 La Carta de Derechos Fundamentales de la Unión Europea sí que menciona, así, el derecho de acceso a los servicios de interés económico general (art. 36), vide al respecto, GIMÉNEZ CASALDUERO, M. y BABIANO AMELIBIA, L., El reconocimiento europeo del derecho humano al agua y al saneamiento: garantía ciudadana para el disfrute de los servicios públicos, en Actas del VIII Congreso Ibérico sobre Gestión y Planificación del Agua, Lisboa, 5 a 7 de diciembre de 2013, Fundación Nueva Cultura del Agua, Zaragoza, 2013.
} 
bilidad generales del abastecimiento domiciliario. Sigue sin reconocerse obviamente un derecho subjetivo pleno, exigible y ejecutable, por las estrictas limitaciones competenciales -materiales y formales- del Derecho comunitario en este punto, pero sí que se fortalece la visión inclusiva, democrática y plenamente humanitaria del derecho al agua, estableciendo auténticas obligaciones de fin para los Estados, de mejora efectiva del acceso y de garantía universal mínima en su disfrute.

El reconocimiento del derecho humano al agua y al saneamiento se materializaría en un deber de prestación para los Estados miembros de garantizar y satisfacer el derecho de las personas al agua potable, segura y limpia, sin discriminación de ningún tipo, es decir, obligándoles a proporcionar el suministro domiciliario de agua y saneamiento como un "servicio" (de interés económico general), cuya prestación deben garantizar a través de las modalidades (de gestión) que prevea el derecho interno, pero no bajo las reglas (estrictas) del mercado ${ }^{18}$.

C. Proyección y construcciones dogmáticas a nivel interno: el derecho al agua como expresión de la garantía constitucional a un "mínimo existencial"

Es lógico que, a falta de reconocimientos internacionales expresos, y con las limitaciones, formales y materiales, comunitarias reseñadas, nuestro Derecho interno, encabezado por el texto constitucional de 1978, no reconozca tampoco expresamente el derecho humano al agua potable. Quizás porque, como se ha sostenido, la indudable consideración del agua como dominio público haya hecho innecesaria la configuración del acceso como auténtico derecho subjetivo a su utilización y consumo ${ }^{19}$. El uso público o aprovechamiento común del agua ha sido tradicionalmente libre y gratuito, y así sigue siendo, siempre y cuando "no se produzca una alteración de la calidady caudal de las aguas", y se respete "el régimen normal de aprovechamiento" (art. 50.2 del Real Decreto Legislativo 1/2001, de 20 de julio, por el que se aprueba el Texto Refundido de la Ley de Aguas, en adelante TRLA). Pero el abastecimiento específico a las poblaciones y el consiguiente suministro domiciliario de agua potable es el primero de los aprovechamientos especiales o privativos, sujeto por tanto a título habilitante de intervención. En el primer caso nos encontraríamos ante un supuesto o proyección de utilización de bienes o recursos comunes y en el segundo, ante un efectivo derecho subjetivo al suministro.

Difícilmente cabe hablar, pues, de un auténtico, genérico y efectivo derecho fundamental al agua, tutelado específica y adecuadamente por nuestro ordenamiento jurídico vigente, más allá de que obviamente quepa inducirlo sin problemas de algunos de los que nuestra Constitución sí consagra así expresamente, empezando

\footnotetext{
18 GIMÉNEZ CASALDUERO, M. y BABIANO AMELIBIA, L. (2013: 335).

19 MENÉNDEZ REXACH, Á. (2015: 199).
} 
por el nuclear derecho a la propia vida (art. 15) $)^{20}$. Que el TRLA garantice el uso libre y gratuito de las aguas continentales no equivale, lógicamente, a un derecho subjetivo a su aprovechamiento (final), aún compartido ${ }^{21}$. Las facultades de exigencia ciudadana se proyectan no tanto sobre el recurso como sobre las obligaciones de prestación por parte de los poderes públicos responsables, en principio los entes municipales. Pero no cabe aquí hablar, en todos los casos, de la satisfacción de necesidades vitales (puesto que es posible que un concesionario de aguas, que evidentemente tiene derecho, y un derecho subjetivo, a su aprovechamiento, ni siquiera las aproveche personalmente, o las destine a usos que difícilmente encajarían en el contenido nuclear de este posible derecho humano al agua).

A partir de estas premisas, la construcción teórica de un posible derecho al agua potable y al saneamiento se ha llevado a cabo por la doctrina a través de la agregación o solapamiento de las previsiones de los diferentes grupos normativos confluyentes (dotaciones por habitante, servicio municipal obligatorio, calidad del agua potable, abastecimiento y saneamiento como servicios necesarios para la consideración del suelo como urbano y existencia de una vivienda digna $)^{22}$, dejando de lado las previsiones estatutarias de nueva generación sobre la posible existencia (regional) del mismo, en general desactivadas por el TC, negando su consideración como derecho subjetivo y reduciendo su funcionalidad programática sólo a los respectivos poderes públicos autonómicos ${ }^{23}$.

Pero seguramente, y en la perspectiva que interesa a este estudio, la consideración del agua como patrimonio común, como mínimo vital existencial, más allá de su carácter objetivo como objeto de prestaciones públicas, y de ahí las limitaciones de intervención material a nivel comunitario, exija superar esta dicotomía regulatoria que, por ejemplo, dejaría "en fuera de juego" a aquéllos grupos o personas vulnerables que teniendo derecho al abastecimiento, pero no al uso común general ${ }^{24}$, no lo

20 Y lógicamente interrelacionarlo con otros derechos básicos como el derecho a la protección de la salud (art. 43) y el derecho a una vivienda digna (art. 47), aunque éstos se encuentren ya en la categoría de principios rectores de la política social y económica, y no entre los derechos fundamentales con protección reforzada.

21 Cabe recordar así, por ejemplo, que según el art. 40.4 TRLA, los planes hidrológicos, que serían los instrumentos específicos de concreción de las dotaciones de agua para abastecimiento - de lo que dependería, en el fondo, la garantía sustantiva del acceso ciudadano- no crean, por sí solos, derechos (subjetivos) en favor de particulares o entidades (y por ello, su modificación, encuadrada dentro de las potestades administrativas de innovación normativa, tampoco da derecho en principio a indemnización).

22 Así, y destacadamente, MENDÉNDEZ REXACH, Á. (2015: 201 y ss.).

23 Vide. MELLADO RUIZ, L., Aguas y ordenación del territorio en el contexto de la reforma estatutaria, Comares, Granada, 2010.

24 Sobre la inadecuación general de la categoría del uso común, por su contenido, para asumir el papel institucional que podría corresponder a un derecho al agua concebido como derecho subjetivo, y con 
recibirían por no poder pagar las tarifas correspondientes (al tratarse en el fondo de servicios económicos de interés general no totalmente gratuitos $)^{25}$.

Reside aquí el acierto de la reforma legislativa andaluza que comentamos. La interrelación de ambas perspectivas o dimensiones, aún sin un reconocimiento explícito del derecho al agua como derecho humano o como derecho fundamental, justificaría no sólo el reforzamiento de las obligaciones públicas de abastecimiento, suministro y saneamiento (sí exigibles jurídicamente), sino la "cobertura" de aquéllas situaciones de especial vulnerabilidad, exclusión o pobreza para el acceso retributivo más que al servicio a un recurso natural esencial para la propia existencia ${ }^{26}$. Como se ha señalado a nivel internacional, el derecho a un servicio de agua y saneamiento, aparte de la calidad y la accesibilidad, ha de tener un precio que cada persona pueda pagar sin reducir sus posibilidades de adquirir otros bienes y servicios esenciales ${ }^{27}$.

La caracterización de este acceso mínimo de subsistencia como auténtico derecho subjetivo de base legal, aún desde el mantenimiento genérico de la naturaleza demanial de los recursos hídricos y de la configuración de los servicios del agua como servicios públicos (de prestación local, aunque de organización discrecional, y por ello motivada), plantea obviamente el grave problema actual, que desarrollaremos, sobre la verdadera "asequibilidad" de los servicios públicos básicos, y en este caso, sobre la disponibilidad universal de un mínimo de agua potable (con independencia del pago o no de las tarifas correspondientes, de la situación socioeconómica o de la efectiva capacidad de pago de los usuarios).

Este planteamiento transaccional se apoyaría, en última instancia, y como legitimación operativa, en pilares fundamentales de nuestro propio ordenamiento

contenidos semejantes a los articulados a nivel internacional, vide EMBID IRUJO, A. (2006: 34 y ss.).

25 En este sentido, ya se había avanzado con acierto que "la necesaria consideración económica que debe tener la utilización del agua, y, con ella, el resto de los recursos naturales, no equivale a que se reduzca todo - desde la perspectiva jurídica- a una mera conclusión coherente con los planteamientos economicistas previos", EMBID IRUJO, A., "El derecho al agua en el marco de la evolución del derecho de aguas", en A. EMBID IRUJO, El derecho al agua, Thomson-Aranzadi, Pamplona, 2006, p. 18.

26 Se ha señalado así que "puesto que el agua potable y el saneamiento son indispensables para la vida y la salud, y fundamentales para la dignidad de toda persona, es fácil advertir la corrección de considerar el acceso al agua potable y al saneamiento como integrantes del derecho humano al agua, lo que es especialmente importante destacar en la época actual, sumida en una situación de crisis cuyas causas básicas radican en la pobreza, las desigualdades y la disparidad en las relaciones de poder, viéndose agravadas por los retos sociales y ambientales, como la urbanización, cada vez más rápida, el cambio climático y la creciente contaminación y merma de los recursos hídricos", MILANS DEL BOSCH Y JORDÁN DE URRIES, S., "El derecho humano al agua y a la seguridad jurídica en el sector y en los consumidores (caso Ter-Llobregat)", en https://www.cuatrecasas.com/es/publicaciones/el derecho humano al agua y a la seguridad_juridica_en_el_sector.html

27 Vide. el desarrollo de este enfoque y su plasmación en diferentes instrumentos internacionales en el Informe especial al Parlamento del Defensor del Pueblo andaluz de Diciembre de 2015 sobre "Servicios de suministro de agua. Garantías y derechos", especialmente págs. 32-45. 
constitucional. Genéricamente, en la consideración del Estado como social ${ }^{28}$, en un marco de prevalencia axiológica de los derechos fundamentales que lo inspiran y sostienen $^{29}$. Y más específicamente, en la propia dignidad de la persona humana que, junto con los derechos inviolables que le son inherentes, constituye el primero de los fundamentos del orden político y de la paz social (art. 10.1 CE) $)^{30}$.

D. Síntesis y propuestas: el agua como bien común y su acceso como mínimo vital

Desde esta primera perspectiva formal o calificatoria, cabría concluir señalando que el agua no es (sólo) un bien (económico) o un recurso (esencial), sino un patrimonio común de la Humanidad ${ }^{31}$. Su esencialidad puede trascender hoy, sin problemas, las propias categorías conceptuales y dogmáticas propias de los sistemas jurídicos internos. Como se ha sostenido en relación precisamente con la afección del cambio climático sobre los recursos hídricos, los problemas globales demandan soluciones también globales, supranacionales, en torno a categorías y formulaciones que superen las concepciones localistas, exclusivas y trasnochadas de un derecho al agua que nunca será efectivo como tal si la organización política, la organización territorial o la distribución de competencias dificultan la utilización del recurso, para usos vitales y humanos, allí donde fuese necesario ${ }^{32}$.

El dominio público es, lógicamente, una construcción jurídica de tutela o protección de determinados bienes o categorías de bienes, pero que en principio, como sucede con el agua, reúnen todas las características para su consideración como bienes privados. Sus limitaciones tuitivas, en el marco obvio de la respectiva normación interna positiva y de un enfoque de sostenibilidad meramente intrageneracional, como la inexistencia de consecuencias competenciales, las distorsiones derivadas del solapamiento entre subordenamientos sectoriales o su falta de correlación con situa-

28 Vide., así, MENÉNDEZ REXACH, Á., El derecho al agua en la legislación española, en F. LÓPEZ MENUDO (coord.), Derechos y garantías del ciudadano. Estudios en homenaje al Profesor Alfonso Pérez Moreno, Iustel, Madrid, 2011, especialmente p. 288 y ss.

29 Por ejemplo, RODRÍGUEZ-ARANA MUÑOZ, J., "Dimensiones del Estado social y derechos fundamentales sociales", en Revista de Investigaciones Constitucionales, Vol. 2, núm. 2, (2015), pp. 31-62.

30 Como se ha dicho, desde una perspectiva funcional, sistémica y "actualizada", es preciso interpretar de forma sistemática el Título I de la Constitución, evitando trazar en su interior fronteras cerradas entre sus partes que ensalcen los derechos de primera generación y degraden los de segunda y tercera generación, cuando lo cierto es que muchos se combinan y complementan en la protección de los mismos bienes jurídicos, VAQUER CABALLERÍA, M., "Derecho a la vivienda y garantía de un mínimo vital: algunas propuestas", en El Cronista del Estado Social y Democrático de Derecho, núm. 48, (2014), p. 36.

31 En el mismo sentido, por ejemplo, que la atmósfera, que sí se declara a nivel interno, en la Ley 34/2007, de calidad del aire y protección de la atmósfera, como "un bien común indispensable para la vida respecto del cual todas las personas tienen el derecho de su uso y disfrute y la obligación de su conservación".

32 MONTORO CHINER, M.J. (2009: 229). 
ciones jurídicas individualizadas sobre los bienes, conllevan la imposibilidad institucional de enlazar a su funcionalidad la existencia efectiva de un derecho fundamental y universal a un abastecimiento mínimo de agua potable. Como mucho, cabría distinguir entre la dimensión individual y la dimensión colectiva del recurso: a escala individual, determinadas aguas pueden ser privadas (y no sólo en aprovechamiento sino, excepcionalmente, en titularidad), pero a escala global o colectiva es evidente que nos encontramos ante un recurso natural indispensable para la vida, en definitiva, ante un bien público global ${ }^{33}$.

Su regulación no sólo debería trascender, así, en un plano de progresiva uniformización internacional sobre su protección, las propias categorías domésticas, sino transitar, en el mismo orden interno, hacia postulados más "sociales" de protección efectiva de todas las situaciones jurídicas individualizadas, lógicamente en diferente graduación, más allá de las referencias positivas a la exigibilidad local del servicio.

Su consideración como bien esencial y como patrimonio común y global ha de completar, pues, la dimensión estrictamente prestacional y económica del servicio, acogiendo, como se sostiene aquí, la existencia de un núcleo mínimo constitucional que el legislador no podría afectar o disminuir, vinculado directamente a la dignidad de la persona. Como se ha afirmado, resulta cada vez más incuestionable, y con apoyo jurisprudencial progresivo, la existencia en los diversos derechos constitucionales de dimensión social de un "núcleo mínimo inviolable", incluso por el legislador, estatal o autonómico, ya se trate del contenido esencial de los derechos del art. 53.2 CE, ya del "mínimo vital" de los recogidos en los arts. 39 y ss $^{34}$. Mínimo vital al agua que si tiene una dimensión negativa o de límite ${ }^{35}$, tendrá también una positiva o de garantía, de (posible) reconocimiento legal directo, superpuesto a la consideración positiva del recurso y a la calificación ordinaria - por económica- del servicio, del derecho de cualquier persona a un mínimo existencial de agua potable, fundamentalmente las personas en estado de necesidad, pobreza o exclusión social.

33 MENÉNDEZ REXACH, Á. (2012: 189).

34 PONCE SOLÉ, J., "El Estado social y democrático de Derecho ante la austeridad y los recortes sociales: la jurisprudencia del Tribunal Constitucional y su interés para el caso español”, en Revista de Derecho Constitucional Europeo, núm. 23, (2015).

35 En general, sobre los límites constitucionales generales a la regresividad en materia de derechos sociales y al cambio de modelo social sin modificación previa de la Constitución, basados precisamente en la existencia de un núcleo mínimo indispensable y absoluto de los derechos sociales, puede verse PONCE SOLÉ, J., El derecho y la (ir)reversibilidad limitada de los derechos sociales de los ciudadanos: las líneas rojas constitucionales a los recortes y la sostenibilidad social, Instituto Nacional de Administración Pública, Madrid, 2013, así como el conjunto de estudios contenido en J. L. PIÑAR MAÑAS, (coord.), Crisis económica y crisis del Estado de bienestar. El papel del Derecho Administrativo, Reus, Madrid. 
Si se puede defender la existencia (aún implícita en el texto constitucional) de unos estándares mínimos de prestación social como auténticos derechos subjetivos perfectos ${ }^{36} \mathrm{o}$, más genéricamente, de un derecho fundamental a un mínimo existencial $^{37} \mathrm{o}$ a la asistencia vital en caso de necesidad ${ }^{38}$, con más razón cabrá sostener la virtualidad jurídica (como derecho de resultado, no a la gestión pública del servicio, sino al acceso general al recurso) del abastecimiento universal mínimo del elemento o recurso vital más esencial seguramente, el agua, en tanto bien común ${ }^{39}$.

La existencia digna demandaría, lógicamente, la densificación, el desarrollo y la materialización de muchos de los derechos sociales y de prestación contenidos en la Constitución, más allá lógicamente de los derechos de libertad configurados -y protegidos- como fundamentales ${ }^{40}$. La existencia física, en sí, exige directamente que cualquier persona tenga derecho a un mínimo de agua potable ${ }^{41}$. No es, pues, una

36 Vide. NOGUEIRA LÓPEZ, A. y ARIAS MARTÍNEZ, M. A., "Blindar el Estado social: una mejora regulatoria para un tiempo de crisis," en VV. AA., Estructuras administrativas y racionalización del gasto público. Problemas actuales de la expropiación forzosa. La reforma de los entes locales en Italia en el contexto de la crisis económica. Actas del VII Congreso de la Asociación Española de Profesores de Derecho Administrativo, Tarragona, 10 y 11 de febrero de 2012, INAP, Madrid, 2012.

37 Vide. GARRO FERNÁNDEZ-VALMAYOR, J. L., "Mínimo existencial y jurisprudencia. Hacia la construcción jurisprudencial de un derecho fundamental”, en E. GARCÍA DE ENTERRÍA MARTÍNEZ-CARANDE y R. ALONSO GARCÍA (coords.), Administración y justicia. Un análisis jurisprudencial. Liber amicorum Tomás-Ramón Fernández, Civitas, Madrid, 2012, pp. 3825-3850.

38 Vide. genéricamente en este sentido, CARMONA CUENCA, E., "Los derechos sociales de prestación y el derecho a un mínimo vital", en Nuevas Politicas Públicas. Anuario multidisciplinar para la modernización de las Administraciones Públicas, núm. 2, (2006), pp. 172-197.

39 Por su reconocimiento constitucional implícito opta, por ejemplo, RODRÍGUEZ ÁLVAREZ, A. (2018: 28), sobre la base de la aplicación efectiva del art. 10.2 CE, y desde una propuesta además de calificación sistémica como derecho fundamental.

40 Así, con el máximo aprovechamiento, VAQUER CABALLERÍA, M. (2014: 34 y ss.). Aboga el autor, al final, por la propia introducción, en una eventual reforma constitucional, de un derecho fundamental de todas las personas a disfrutar de alojamiento, vestido, alimentos y las demás condiciones mínimas para poder vivir dignamente y desarrollar libremente su personalidad, consagración que tendría consecuencias positivas como la reserva al Estado, mediante ley orgánica, de su desarrollo, el blindaje de las condiciones mínimas exigibles, incluso frente al legislador ordinario y su tutela judicial reforzada. Del mismo, posteriormente, "Retos y oportunidades para una política cabal de vivienda tras la crisis económica”, en T. DE LA QUADRA-SALCEDO FERNÁNDEZ DEL CASTILLO, Los servicios públicos tras la crisis económica. En especial la asistencia sanitaria en la Unión Europea, Tirant lo Blanch, Valencia, 2017, p. 244 y ss.

41 Dentro de la garantía de un "mínimo existencial" que se derivaría del principio del Estado social habría de incluirse necesariamente, en definitiva, el derecho a disponer de agua suficiente para la satisfacción de las necesidades vitales, porque es inherente al derecho a la vida y está implícito en algunos de los derechos sociales fundamentales (protección de la salud, medio ambiente y vivienda), MENÉNDEZ REXACH, Á. (2015: 201). 
cuestión de dignidad, sino más bien de salud, seguridad y subsistencia última ${ }^{42}$. De vida, en definitiva (art. $15 \mathrm{CE}$ ).

\section{Aproximación al contenido y objeto del derecho al agua}

Desde el punto de vista de su contenido, y dada la inexistencia de reconocimientos específicos y plenos a nivel interno, es evidente que las prestaciones y el objeto de este necesario derecho vital al agua deberán extraerse de las construcciones dogmáticas realizadas por los autores en los últimos años, sobre la base de las declaraciones internacionales más arriba reseñadas.

Con carácter general se ha señalado que el derecho humano al agua debería traducirse en el derecho universal a un abastecimiento de agua potable de forma suficiente y continua, para el uso personal y doméstico, incluyendo como mínimo el agua para beber, la preparación de alimentos, la limpieza del hogar y vestido y la higiene personal, teniendo en cuenta la recomendación de la Organización Mundial de la Salud que establece como referencia entre 50 y 100 litros de agua por persona y día para garantizar que se cubren las necesidades más básicas. Más allá de la concreción efectiva de los distintos elementos o facetas del mismo (básicamente, la cantidad y la calidad del recurso), la clave en su configuración reside, obviamente, en la garantía de "accesibilidad", que vendría a tener dos dimensiones interrelacionadas: una física y otra económica. En cuanto a la primera, haría referencia a la susceptibilidad de acceso al agua, para uso personal y doméstico, y con unas condiciones mínimas de salubridad y potabilidad, por parte de todas las personas y usuarios, al menos en sus hogares, a través del uso, establecimiento o conexión de redes apropiadas de distribución y evacuación de aguas, o, al menos, un acceso físico a una fuente de agua. La accesibilidad económica se referiría a la asequibilidad efectiva a un mínimo existencial de agua, si no gratuito, a costes razonables, y con la posibilidad de excepción equitativa de determinados grupos o personas especialmente vulnerables. Implicaría además la imposibilidad de que el pago de los servicios de agua y saneamiento impidiera disfrutar de otros derechos humanos, como la vivienda o la alimentación. $\mathrm{Su}$ consecución pasaría, entre otras fórmulas, por una tarificación justa, progresiva y eficiente, una posible bonificación, a través de fórmulas estimativas, de determinadas situaciones personales o familiares, el establecimiento de precios versátiles y flexibles,

42 Como se ha dicho, es innegable, más allá de las materializaciones positivas singulares, la conexión del derecho al agua con unas condiciones humanas mínimas de existencia, de tal forma que el derecho es instrumento para la realización o aseguramiento de dichas condiciones. No se trata, entonces, de vincular también el ejercicio del derecho al agua con una actividad económica o social, sino de proporcionar elementos para que, simplemente, la vida pueda desarrollarse y con unas condiciones básicas en el sentido de mínimas (pero suficientes) de calidad, EMBID IRUJO, A. (2006: 22). 
diferenciando las condiciones económicas y sociales de la población, la modulación gradual del principio general de recuperación de costes, etc.

Pero la accesibilidad real, en la que se fundamentaría hoy la posible universalización del acceso al agua (principio de disponibilidad), debería articularse además sobre otras dos dimensiones o exigencias instrumentales y superpuestas: la ausencia de discriminación de cualquier tipo en el abastecimiento, acceso o suministro y el acceso a la información o transparencia de las decisiones sobre los servicios del agua ${ }^{43}$.

Se trataría de asegurar, pues, no sólo un acceso físico y económico efectivo y continuado al abastecimiento, suministro o disponibilidad de un mínimo de agua potable y de calidad, sino de garantizar positivamente su carácter universal (personal y territorialmente) y la naturaleza abierta y participativa de los instrumentos de ordenación y gestión. Como se ha podido definir en el ámbito internacional, el derecho humano al agua sería, pues, "el derecho de todos a disponer de agua suficiente, salubre, aceptable, accesible y asequible para el uso personal y doméstico" ".

En este sentido se ha podido señalar que el derecho humano al agua se estructuraría, en el fondo, como un sistema de libertades, garantías y limitaciones, incluyendo el derecho a mantener el acceso a un suministro de agua necesario, a no ser objeto de injerencias o limitaciones injustificadas (es decir, a no sufrir cortes arbitrarios de suministro) o claramente contrarias a la dignidad humana y al mínimo existencial reconocido constitucionalmente ("desahucio hídrico"), así como genéricamente a un abastecimiento y gestión del agua que ofrezca a la población iguales oportunidades de disfrutar del recurso ${ }^{45}$. La forma de acogimiento del derecho al agua en el ordenamiento andaluz enlaza inmediatamente con esta problemática actual, puesto que aunque no se discute que carezca, por lógica insuficiencia competencial, de la naturaleza formal -expresa o implícita- de derecho fundamental, lo que impediría lógicamente intervenciones desproporcionadas o contrarias al comentado "núcleo mínimo" de protección de los derechos fundamentales (más claramente si se entiende que se trata de un auténtico y expreso derecho humano), sí que se vincula legalmente a un "mínimo vital" de todos los ciudadanos, proscribiendo entonces situaciones de

43 Vide. AGUIAR RIBEIRO DO NASCIMENTO, G. (2018: 254). Como ha señalado el propio Parlamento Europeo, es preciso que las autoridades competentes de los Estados miembros pongan a disposición de los ciudadanos toda la información relativa a la calidad y la gestión del agua, de manera fácilmente accesible y comprensible, de manera que se informe y se consulte plenamente y a tiempo a los ciudadanos sobre todos los proyectos de gestión del agua, Resolución del Parlamento Europeo de 8 de septiembre de 2015, sobre el seguimiento de la Iniciativa Ciudadana Europea Right2Water.

44 Declaración general del Comité de derechos económicos, sociales y culturales de Naciones Unidas, en su 29ª Sesión, Ginebra, 2002.

45 RODRÍGUEZ ÁLVAREZ, A. (2018: 17). 
indisponibilidad o cese del suministro no tanto por incapacidad o inaccesibilidad física cuanto por insuficiencia económica para el pago de los servicios.

Este conjunto, más o menos definido, de facultades, exigencias o "derechos" incluidos, fundamentalmente a nivel internacional, dentro de lo que podría calificarse como "derecho humano al agua" recae, en el fondo, sobre un objeto (bien) específico, y singular, el agua, que, como se sabe, tiene, según los diferentes ordenamientos jurídicos, su propia -y en muchos casos divergente- naturaleza jurídica. Por ello, en el plano general donde nos movemos, no cabría calificarlo como un auténtico "derecho real" sobre dicho bien, lo que explica, de un lado, la disparidad -y dificultad- internas de aproximaciones al fenómeno y, de otro, como puede verse en el caso de Andalucía, la complementación de la declaración inicial genérica sobre el derecho con la operatividad real del mismo a través no del reconocimiento de situaciones colectivas de acción directa frente al Estado sino de exigencia de prestaciones adecuadas del servicio frente a los poderes públicos específicamente competentes.

Desarrollamos a continuación estos contenidos y probables manifestaciones del derecho al agua como mínimo existencial a propósito del estudio de la nueva disposición legal más arriba reseñada.

\section{ANÁLISIS ESPECÍFICO DE LA INTRODUGCIÓN DE LA CLÁUSULA VITAL AL AGUA EN LA LEGISLACIÓN ANDALUZA DE AGUAS}

\section{Contextualización inicial: la integración entre las políticas hídricas y la respuesta frente al cambio climático}

Como se ha avanzado más arriba, más allá de la discutible - pero común en nuestros legisladores- fórmula de introducción expresa de este derecho en el sistema jurídico andaluz, vía derecho de articulación y con necesidad de complemento y desarrollo, lo cierto es que no resulta improcedente la vinculación inicial -más, su interacción sustantiva-, primero, entre las políticas del agua y las decisiones globales de lucha contra el cambio climático y las alteraciones ecosistémicas generales, y segundo, la fundamentación última del derecho ciudadano al agua como mínimo existencial en un contexto de necesaria reacción trasnacional frente a tales retos.

$\mathrm{Y}$ es que como bien se ha sintetizado, la interacción entre las medidas de mitigación y adaptación frente al cambio climático y las de gestión sostenible y ordenada de las aguas es doble: de un lado, porque mediante la reducción de emisiones y la diversificación energética a las que puede contribuir una política hídrica responsable se habría de contribuir a frenar o limitar el actual calentamiento global del planeta, y de otro, porque la apertura a fuentes de energía limpia o renovable que no requieran 
del uso de los recursos hídricos contribuiría igualmente a paliar su progresiva escasez e irregularidad (territorial y temporal), agudizadas a causa de aquellos fenómenos ${ }^{46}$.

Se hace precisa, pues, una efectiva integración entre la política hidráulica y la energética. Como se dice en la Exposición de Motivos de la Ley 8/2018, que comentamos, en materia de cambio climático la Administración pública debe asumir un papel ejemplarizante, al margen de sus propias e ineludibles obligaciones normativas de ejecución y gestión, en un contexto de promoción de la cultura climática y la transparencia. La transversalidad de las medidas de transición hacia una economía baja en carbono o de adaptación y resiliencia al cambio climático de los distintos sectores socioeconómicos exige una efectiva incorporación de las medidas a adoptar en la planificación sectorial vinculada, con especial mención a la ordenación de los recursos hídricos. Estos son, así, la primera de las áreas estratégicas a los efectos de incorporación de medidas de adaptación, y con el objetivo genérico de reducir los riesgos económicos, ambientales y sociales derivados del cambio climático (art. 11.1), creándose además, y como novedad, el denominado "Registro público de la huella hídrica" de productos, servicios y organizaciones, como registro público, aún voluntario, para la constancia, evaluación y comunicación del consumo de recursos hídricos asociados al ciclo de vida de dichos productos, servicios u organizaciones, producidos, distribuidos o comercializados por cualesquiera sujetos, tanto públicos como privados, del ámbito andaluz (art. 21.1) ${ }^{47}$. Desde el punto de vista complementario de las medidas de mitigación o reducción de las emisiones de gases de efecto invernadero, uno de los objetivos generales básicos es, igualmente, el uso racional y sostenible de los recursos naturales, en especial de los recursos hídricos (art. 35.d).

La ordenación congruente y racional de las políticas e instrumentos hidráulicos resultan por tanto clave en el reto común de lucha contra las crecientes manifestaciones del cambio climático. Frente al agravamiento de sequías e inundaciones, se imponen medidas tanto de adaptación (integración normativa, coordinación en la planificación, incentivación del uso sostenible del agua por los sujetos privados, etc.) como de limitación de emisiones, en un nuevo contexto de superación de la visión clásica de las relaciones, no sólo económicas, entre el hombre y el agua, activo ecosocial, recurso ambiental esencial, pero, innegablemente, y por encima, elemento vital.

46 Vide. GONZÁLEZ RÍOS, I., "Incidencia del cambio climático en los recursos hídricos. Medidas de mitigación y adaptación”, en Revista Aragonesa de Administración Pública, núm. Extraordinario 11, (2009), p. 308. También puede verse el estudio Cambio climático y adaptación de los recursos hídricos, Agencia Europea de Medio Ambiente, Madrid, 2009.

47 La inscripción en el Registro, que tendrá una validez mínima de dos años prorrogables, otorgará el derecho a utilizar el logotipo de la huella hídrica en el establecimiento o en la etiqueta del producto. 


\section{2. $\mathrm{i}$ Es competente la Comunidad andaluza para proclamar este derecho?}

Esta nueva, o al menos reforzada, dimensión "acompetencial", podría decirse, es el fundamento axiológico último del actual acogimiento del derecho humano al agua en la normativa andaluza.

Es evidente que una ley sectorial autonómica, y mucho menos de forma indirecta modificando otra norma, no puede proclamar, reconocer o explicitar la existencia, y su reconocimiento pleno en favor de los sujetos activos, ni de un derecho humano "nuevo" ni de un "derecho fundamental" ausente de forma expresa en la Constitución. Lo mismo que se ha dicho de los grandes principios generales del Derecho, que no se descubren sino que simplemente se desvelan, podría decirse de un derecho humano con innegable reconocimiento internacional, pero es evidente la incapacidad competencial formal de una Comunidad Autónoma para reconocer sectorialmente, aún de forma implícita, y con todas sus garantías ancilares, un nuevo derecho fundamental, aún asociado claramente a otros sí reconocidos.

Pero también es verdad que la Disposición Adicional que comentamos ni proclama directamente la existencia "material" de tal derecho ni parece apoyarse en el posible título competencial sustantivo correspondiente para hacerlo.

Desde la primera perspectiva, y aún con una fórmula ciertamente alambicada, lo que se hace es simplemente enlazar la funcionalidad de una serie de principios generales con la garantía internacional del derecho humano al agua. La ley no reconoce, sino que "describe" cómo determinados principios, de innegable proyección en este grupo normativo, "amparan” la garantía y protección de aquel. No hay, pues, ni reconocimiento - explícito o implícito- ni proclamación directa, que amparara una posible regulación de desarrollo posterior. Podría discutirse, así, la efectividad, necesidad y hasta acierto regulatorios de la fórmula utilizada -fuera, además, de la parte prescriptiva, y no digamos dogmática, de la norma correspondiente-, pero realmente, en su misma ambigüedad, no parece que la proclamación andaluza del derecho humano al agua como mínimo vital contradiga directamente ningún precepto - en términos sustantivos de contenido o formales de capacidad competencialconstitucional o legal (estatal). No obstante, es evidente que la Comunidad Autónoma necesita algún tipo de "base competencial" para, si no proclamar un nuevo derecho ciudadano, justificar el pronunciamiento genérico utilizado y fundamentar el posible desarrollo reglamentario posterior. Y esta podría encontrarse, como se viene comentando aquí, en la existencia constitucional implícita de un auténtico derecho fundamental a un mínimo vital existencial de cualquier persona, traducido, aquí, en un mínimo ineludible de agua para vivir. El enfoque, aún positivo, es ciertamente, y en términos estrictamente jurídicos, más que dudoso. Se trata, nada más y nada menos, 
que de inducir, por un legislador autonómico sectorial, un nuevo derecho fundamental de nuestro texto constitucional, cuya regulación efectiva, en términos de normativa básica de mínimos, correspondería en cualquier caso al Estado (art. 149.1.1 $\left.{ }^{\text {a }} \mathrm{CE}\right)^{48}$. No parece que sea esta, al menos inmediatamente, la intención del legislador andaluz, sino más bien enlazar una declaración genérica, simbólica y desiderativa, en primer plano, con las matizadas posibilidades competenciales de normación efectiva no a través de los instrumentos de desarrollo dogmático sino, más sencillamente, la normativa reguladora de la prestación del servicio en el ámbito local.

No hay, pues, un reconocimiento pleno - mucho menos completo en términos materiales- a nivel autonómico del derecho humano al agua, sino una mera declaración de principios junto con una simple descripción de su operatividad y contenido genéricos, convertida luego, más modestamente, en una remisión reglamentaria para la concreción de las condiciones de prestación del servicio.

La relevancia de la disposición podría radicar, entonces, en la intención de visibilizar o poner en valor un derecho humano en clara proyección positiva, y en su inmediata conexión con la construcción teórica superior de la garantía universal ("metaconstitucional", podría decirse) a un mínimo existencial por todas las personas. La fundamentación axiológica - por encima de la complejidad competencial- del derecho al agua se encuentra así, en la preservación de dicho mínimo vital, pero la concreción -y exigibilidad jurídica- del mismo se remiten, más modestamente, a la propia normativa reglamentaria ordenadora de la prestación a nivel local de los servicios correspondientes. Es dudoso por ello que sobre estos presupuestos (endebles, por teóricos) pudiera regularse de forma plena, como era intención del anterior legislador andaluz, la exigibilidad jurídica universal de este derecho, en el proyectado Reglamento del ciclo integral del agua de uso urbano en Andalucía ${ }^{49}$. El nuevo apartado segundo de la D. A. $16^{\text {a }}$ LAA dice concretamente que las condiciones de prestación y acceso al derecho humano al agua, es decir, los requisitos y presupuestos de materialización de los servicios públicos locales de abastecimiento, serán objeto de desarrollo reglamentario en la disposición administrativa de carácter general que contemple las relaciones entre las entidades de prestación de dichos servicios (públicas o privadas) y los usuarios de los mismos. La prestación -u ordenación- administrativas de los servicios del ciclo integral del agua de uso urbano sí pueden ser objeto, evidentemente, por encima y como marco de las ordenanzas correspondientes, de una reglamentación autonómica general que,

48 Cuestionamiento competencial que demandaría, incluso, y como se ha puesto de manifiesto, una auténtica "política de Estado" sobre el agua en España, vide DELGADO PIQUERAS, F., "La política del agua en España: a propósito de un pacto de Estado", en F. J. JIMÉNEZ DE CISNEROS CID (dir.), Homenaje al Profesor Ángel Menéndez Rexach, Vol. II, Thomson-Reuters Aranzadi, Pamplona, 2018, p. 112.

49 Vide el Documento de Conclusiones finales del proceso participativo para su elaboración, Junta de Andalucía, 5 de noviembre de 2018. 
con las limitaciones competenciales propias del carácter bifronte del régimen local, discipline el régimen jurídico-relacional de dichas prestaciones. Pero no así el "acceso" al derecho humano al agua, que, como tal, no sería objeto del mismo, desde una dimensión nuevamente relacional, sino de pleno ejercicio, en su caso, a nivel individual. Un reglamento autonómico sobre los servicios urbanos del agua no podría establecer así, técnicamente, las condiciones de ejercicio de un derecho subjetivo individual a un mínimo vital de agua, más allá de la evidente conexión de ambas dimensiones, y de la también palpable relatividad de los términos positivos de la disposición que comentamos. A mi juicio, pues, su posible reconocimiento reglamentario expreso, en términos dogmáticos, no habilitaría para su exigibilidad universal y material, como auténtico derecho subjetivo, y por evidente incapacidad competencial autonómica al respecto, más allá de su reconducción funcional hacia la otra posibilidad complementaria de regulación indirecta como prestación local de obligado cumplimiento.

\section{Elementos}

\section{A. Marco axiológico}

a). Funcionalidad de los principios de utilización solidaria del agua, de igualdad de trato y de protección de la salud de los usuarios

Comienza señalando la D. A. 16 ${ }^{\text {a }}$ LAA que el fundamento último axiológico del reconocimiento, aún indirecto o genérico, del derecho humano al agua, en su dimensión de mínimo vital, se ampararía en la operatividad de estos tres grandes principios generales. Principios de diferente naturaleza y proyección, pero informadores genéricamente de la actuación administrativa en materia de aguas y ecosistemas asociados según el art. 5 LAA, y que vendrían a resaltar la dimensión existencial y vital objeto de esta disposición.

Efectivamente, el principio de utilización solidaria del agua, de posible naturaleza dual, ético-jurídica, estaría conectado con su consideración estricta como bien común y universal, susceptible de un uso necesariamente sostenible y racional, tanto desde la perspectiva intrageneracional como intergeneraciona $l^{50}$. El uso responsable, compartido y equitativo del recurso responde, así, al propio interés general subyacente a la naturaleza pública del bien. Su escasez, irregularidad y fragilidad, en línea con la necesaria perspectiva holística en su regulación, imponen, así, fórmulas de

50 Se da así un paso más en la visión, cerrada y cantonalista, que ha predominado en los últimos años en nuestro país en materia de ordenación pública del agua, desde su exclusiva perspectiva territorial. Así se manifiesta, de hecho, en el art. 10.7 del Estatuto de Autonomía andaluz, señalándose como uno de los objetivos generales de la Comunidad "la mejora de la calidad de vida de los andaluces y andaluzas, mediante la protección de la naturaleza y del medio ambiente, la adecuada gestión del agua y la solidaridad interterritorial en su uso y distribución". 
utilización, uso y recuperación de costes fundadas en el necesario principio de solidaridad humana, permitiéndose una justa y equitativa distribución social de los recursos (más si son escasos), una garantía mínima y universal de acceso, una mayor intervención pública en el reequilibrio del ciclo hidrológico, etc. Junto al mismo, también es evidente que el principio constitucional general de igualdad de trato impone a los poderes públicos obligaciones proactivas de evitación de situaciones discriminatorias o inequitativas en la posibilidad de acceso, disfrute y utilización no tanto de los bienes comunes (cuyo disfrute universal y genérico, como derecho directamente exigible, no está previsto expresamente en nuestro ordenamiento jurídico) cuanto de los servicios de interés general establecidos sobre los mismos. En el marco de la reglamentación correspondiente, y en tanto actividad pública prestacional, es evidente que ha de garantizarse la igualdad de trato entre todos los usuarios, y promoverse, en su caso, las medidas de discriminación positiva necesarias ${ }^{51}$. En la alambicada redacción de la Disposición comentada, realmente no es que la igualdad efectiva de trato - pero no el igualitarismo forzoso- ampare la garantía y protección del derecho humano al agua, sino que dicho principio ha de informar necesariamente toda regulación interna que concrete y especifique los mecanismos efectivos de prestación y protección de dicho derecho. Porque, al menos por ahora, y sin reconocimiento expreso, ni puede ser exigible como tal a nivel interno - o autonómico, lógicamente- este derecho, ni su ejercicio demandaría un trato igualitario, sino más bien, y en el marco de la reglamentación correspondiente, la organización y prestación del servicio (local) de materialización prestacional. Finalmente, también resulta patente la conexión del principio general de protección de la salud de los usuarios con la garantía y tutela del derecho humano al agua. Este implica, así, un mínimo vital en el acceso para garantizar la propia existencia, salud y desarrollo de cualquier persona. El agua potable, en una cantidad mínima razonable, no es sólo presupuesto de la salud, sino de la propia existencia física.

En definitiva, se trata de tres principios generales, sí reconocidos expresamente, que enlazarían y tutelarían, como fórmula indirecta de garantía y protección, un derecho humano reconocido, a su vez, en instancias supraestatales. No se declara, así, a nivel interno, un derecho al agua, sino que se explicita la constancia de principios jurídicos fundamentadores de su existencia o reconocimiento "externos".

\section{b). El uso racional del agua como obligación básica de la Administración}

De forma más concreta y positiva, el sustento axiológico de este derecho se apoya también en la finalidad pública de atender las necesidades básicas de consumo doméstico a un precio asequible contenida en el art. 111 bis.2 TRLA.

51 Como se dice en el Documento "El Derecho al agua" de la ONU (2003), "los Estados tienen la obligación de prohibir y eliminar la discriminación por todos los motivos, y de garantizar la igualdad, de hecho y de derecho, en el acceso al agua potable y el saneamiento". 
Sin embargo, tal fundamentación, aún como mecanismo de simple "amparo", exige una adecuada depuración interpretativa. Primero, porque es evidente que el precepto no reconoce, ni indirectamente, la existencia de un posible derecho universal y mínimo al agua: es, de hecho, y más bien, una regla ancilar del mismo régimen económico-financiero de utilización del recurso. Segundo, porque la remisión al mismo está incompleta, y podría dar una impresión aplicativa equivocada: en realidad, el fin u objetivo fundamental perseguido en este punto es la efectividad y garantía del principio de recuperación de los costes de los servicios relacionados con la gestión del agua, vía, fundamentalmente, tributación. Para ello, la Administración con competencias en materia de suministro de agua, que sería en principio la Administración local, no la autonómica - con lo que de nuevo se imbrican aquí títulos y ámbitos competenciales diferentes a la hora de regular, o al menos prever, la existencia de un derecho a una prestación mínima vital de agua- ha de establecer las estructuras tarifarias con tramos de consumo, es decir, planificar una tributación progresiva, elástica o secuencial, con la finalidad, y aquí se enlaza con la funcionalidad de la previsión que comentamos, de "atender las necesidades básicas a un precio asequible y desincentivar los consumos excesivos". Fácilmente se colige que el precepto no prevé, genéricamente, un derecho humano o universal al acceso, en una cantidad mínima, sino la conexión del principio de progresividad fiscal con dos dimensiones o finalidades no directamente recaudatorias, la garantía de prestación de los servicios básicos a precios asequibles y la penalización de consumos excesivos. A pesar de ello, está claro que atender las necesidades básicas de la población de consumo doméstico de agua, a un precio razonable y accesible, tiene una inmediata relación con la proclamación, al menos en el plano internacional, del derecho al agua ${ }^{52}$.

\section{B. Contenido}

Siguiendo la línea marcada a nivel internacional, la D. A. 16 $6^{\text {a }}$ LAA introduce también su propia conceptualización y contenido del derecho humano al agua. Aparte de este carácter realmente reiterativo o declarativo, tampoco hay aquí una proclamación formal del mismo, sino la simple descripción de su dimensión material. Sus elementos integradores serían los siguientes.

\section{a). Accesibilidad universal}

La primera nota característica es, lógicamente, la garantía de accesibilidad universal y general a un mínimo de agua por persona. La accesibilidad, tanto física

52 Así se ha reflejado, además, en alguna otra norma autonómica de nueva generación, como la Ley 10/2014, de 27 de noviembre, de Aguas y Ríos de Aragón, entendiendo como "uso sostenible del agua", uno de los principios orientadores de la actuación política y administrativa regional, "la protección a largo plazo de los recursos hídricos disponibles, lo que supone su utilización racional y solidaria, y el fomento de la reutilización y el ahorro del agua, garantizando el uso doméstico de la misma mediante un precio asequible y social'. 
como económica y sin discriminación, tiene como presupuestos, precisamente, la necesaria protección de los recursos hídricos, la garantía de sostenibilidad y disponibilidad futuras y la asequibilidad del precio. Implica, en el fondo, que todos los seres humanos tienen derecho al agua, genéricamente en tanto requisito vital, y específicamente, como destinatarios de un servicio público. El derecho al agua, como derecho al acceso al suministro de agua para el consumo humano, presenta, así, dos perspectivas claves en su protección: el suministro del servicio considerado esencial y la utilización de un recurso natural indispensable. En ambas, el precio (accesibilidad económica) aparece como elemento fundamental. La propia garantía de la prestación del suministro de agua como derecho básico y de la protección de los recursos hídricos exige una fijación de precios adecuada: asequible, como derecho humano, y sostenible, con utilización eficiente de los recursos naturales ${ }^{53}$.

\section{b). Carácter domiciliario}

Más que disponibilidad o accesibilidad física o territorial (que estarían relacionadas más bien con el "uso común" del recurso), esta "configuración autonómica" del derecho al agua guarda inmediata relación, como ya se ha comentado, con la caracterización local del servicio de abastecimiento de agua a poblaciones, que incluye específicamente la distribución de agua potable en baja, articulado positivamente como servicio público municipal reservado (art. 86.2 LRBRL). A efectos meramente descriptivos, pues, se entiende la accesibilidad como el derecho al suministro domiciliario de agua ${ }^{54}$, a la prestación específica en cada uno de los edificios o estructuras habitacionales de la población, y en principio con independencia del carácter urbano o no del suelo ${ }^{55}$, pero consecuentemente en los términos y condiciones establecidos en

53 LÓPEZ DE CASTRO GARCÍA-MORATO, L., "Sobre el derecho al agua a un precio asequible y sostenible”, en F. J. JIMÉNEZ DE CISNEROS CID (dir.), Homenaje al Profesor Ángel Menéndez Rexach, Vol. I, Thomson Reuters-Aranzadi, Pamplona, 2018, p. 349

54 Desde esta perspectiva, sí es evidente, y conocido, el reconocimiento legal de la existencia de un auténtico derecho subjetivo de los vecinos a exigir la prestación de los servicios municipales obligatorios (art. 18.1.g) LRBRL), entre los que se encuentra el abastecimiento domiciliario de agua potable (art. 26.1.a) LRBRL).

55 En este sentido, por ejemplo, GARCÍA RUBIO, F., "Régimen jurídico-administrativo del servicio de abastecimiento de agua a las poblaciones y sus vinculaciones urbanísticas y de servicio público", Práctica Urbanística, núm. 120, (2013), pp. 112-127. Existe ya jurisprudencia incluso que ha reconocido este derecho a viviendas ubicadas en suelo no urbanizable, "lo cual parece discutible, al menos en cuanto ese reconocimiento implique el derecho a conectarse a la red municipal de abastecimiento, pues podría conllevar la clasificación como urbanos de terrenos situados fuera de la malla urbana. Una vivienda en suelo no urbanizable debe tener suministro de agua para que reúna las condiciones exigibles de habitabilidad, pero ese suministro no tiene que proceder necesariamente de la red municipal', MENÉNDEZ REXACH, Á. (2015: 218). Una cosa es que el servicio sea de obligada prestación y otra que el Ayuntamiento esté obligado a sufragar y prestar el mismo a cualquier vivienda, con independencia de su localización, ya que hay que superponer realmente el grupo normativo sobre los servicios públicos obligatorios con el urbanístico de la existencia de determinados servicios y dotaciones para la clasificación 
la propia normativa reguladora ${ }^{56}$. Igualmente, esta prestación deberá realizarse de acuerdo con los clásicos - pero ineluctables- principios generales informadores de la actividad prestacional de servicio público (continuidad, regularidad, universalidad e igualdad de acceso o recepción de la prestación de que se trate). Realmente, en la actualidad, el abastecimiento de agua potable se realiza, como se sabe, a través de redes de suministro que convierten al titular del derecho humano al agua en un mero usuario, y donde han de cumplirse los citados principios generales, lo que sin embargo no ha de implicar, en principio, la incompatibilidad dogmática entre ambas perspectivas o dimensiones ${ }^{57}$.

El carácter domiciliario del abastecimiento -y la concreción del derecho al agua como derecho a la prestación de los servicios públicos correspondientes- guarda relación también con las exigencias de la normativa higiénico-sanitaria y de habitabilidad de las viviendas (en tanto que la disponibilidad de agua en las viviendas es seguramente el factor básico de salubridad en ellas) ${ }^{58}$, así como, tal y como se apuntó

específica del suelo. Hay que tener en cuenta no obstante, y como se ha estudiado, la íntima conexión entre la normativa urbanística y la ordenación de los recursos hídricos, en tanto que el abastecimiento de agua es uno de los servicios mínimos para la clasificación del suelo como urbano, la garantía del suministro uno de los criterios básicos de utilización del mismo y la suficiencia de recursos hídricos condición inexcusable -y según el TS, informe vinculante- para la transformación del suelo o, más específicamente, las actuaciones de urbanización del mismo (arts. 20.1.c y 22.3.a) del Real Decreto Legislativo 7/2015, de 30 de octubre, por el que se aprueba el Texto Refundido de la Ley del Suelo y Rehabilitación Urbana). En relación a dicho informe puede verse, recientemente, MUÑOZ AMOR, M. M., "El informe de las Confederaciones Hidrográficas sobre suficiencia y disponibilidad de agua en el marco del cambio climático y de la buena administración", en F. J. JIMÉNEZ DE CISNEROS CID (dir.), Homenaje al Profesor Ángel Menéndez Rexach, Vol. II, op. cit., p. 399 y ss.

56 Cabría plantear entonces, a la luz de la definición acogida ahora por la LAA, si el derecho a un suministro mínimo de agua habría de reducirse, aparentemente, a los domicilios, en sentido estricto, es decir, al abastecimiento para el consumo doméstico, como dotación para las necesidades básicas a particulares, excluyendo entonces el abastecimiento para actividades económicas, de mayor o menor envergadura. El sentido del precepto así lo avalaría. No hay, como comentamos, un reconocimiento genérico legal de un derecho humano y fundamental de acceso al agua, con independencia, pues, de los usos o finalidades, sino una garantía mínima indirecta, vía redirección a la normativa local sobre el servicio, del acceso personal y doméstico a un mínimo existencial de agua. Pero tampoco se excluiría entonces la regulación propia del conjunto de usos del recurso, partiendo de su carácter demanial, y hasta llegar a la normativa local específica reguladora del régimen de abastecimiento y distribución. Y finalmente, ¿̇se entendería por uso domiciliario, y por tanto garantizado, el suministro dotacional a edificios de vivienda donde a la vez se pueden desarrollar determinadas actividades económicas? ¿Cómo se controlaría que el agua suministrada se dedica a usos domésticos y no a otros?, etc. Como se ha dicho en este sentido, "la preferencia absoluta del consumo humano sobre cualquier otro uso está plenamente justificada, pero su prestación en red (municipal o supramunicipal) puede producir algunas distorsiones, ya que a través de la red se abastecerá realmente a todos los usuarios conectados a ella, con independencia de la actividad que realicen y del destino de las aguas", MENÉNDEZ REXACH, Á., "El derecho al agua en España”, en Revista Europea de Derechos Fundamentales, núm. 25, (2013), p. 220.

57 Vide LOPERENA ROTA, D. (2007: 90).
58 Vide, así, MENÉNDEZ REXACH, Á. (2015: 208 y ss.). 
más arriba, con las propias exigencias de calidad del agua para el consumo huma$\mathrm{no}^{59}$.

\section{c). Disponibilidad y unicidad económica}

Pero no hay, como parecería hasta ahora, una pura remisión implícita a la normativa sobre el servicio local de abastecimiento, sino que se añade, de acuerdo con la orientación general del precepto, la condición expresa de que el suministro domiciliario de agua lo sea a un precio accesible y unitario. Se enlaza, así, la accesibilidad física con la accesibilidad económica, garantizándose la propia disponibilidad del recurso (que vendría a demandar el carácter continuo y suficiente del abastecimiento). En tanto servicio público local obligatorio es evidente la necesidad de garantía universal en su acceso, previéndose su accesibilidad económica, aunque no, lógicamente, su gratuidad (por la necesaria repercusión en el precio no tanto del "valor" del agua, no mensurable realmente, sino de la actividad administrativa de prestación, suministro y utilización de obras hidráulicas y, sobre todo, de los costes ambientales implícitos). Y en cuanto recurso natural unitario (dominio público estatal integrado en el ciclo hidrológico), se añade la necesidad de que su precio también responda a criterios "unitarios" de tratamiento y gestión (art. 14 TRLA), necesariamente compatibles, de nuevo, con la especificidad, singularidad y progresividad de la concreción reglamentaria municipal del régimen económico del servicio. El precio del agua debería ser "unitario", en el sentido de garantizar un mínimo uniforme y universal de racionalidad y sostenibilidad en su tratamiento y acceso ${ }^{60}$, aunque adaptado, modulado o desarrollado luego en función de las características y condiciones tanto del ámbito territorial de prestación como personal de exigencia o disfrute del servicio.

Reside aquí, obviamente, y desde este perspectiva general del derecho al agua no como derecho subjetivo individual sino como mínimo vital indispensable, la mayor problemática asociada a la posible implementación, tras su mera declaración programática, del acceso sin restricciones, tampoco económicas, a un mínimo existencial de agua potable, aún en los casos más extremos de carencia o insuficiencia -

59 Es necesario tener en cuenta, pues, las estrictas normas comunitarias sobre la calidad del agua, que garantizan, ante todo, un elevado nivel de protección de la salud pública y del medio ambiente, vide, por todos, TARRÉS VIVES, M., "La calidad del agua como concepto jurídico", en M. J. MONTORO CHINER (coord.), El agua: estudios interdisciplinares, Atelier, Barcelona, 2009, pp. 23-35 y ORTÍZ DE TENA, M. C., "La protección de la calidad de las aguas", en Revista Andaluza de Administración Pública, núm. 71-72, (2008), p. 67 y ss.

60 La propia LAA señala expresamente que la primera obligación de los usuarios del agua es utilizarla con criterios de racionalidad y sostenibilidad (art. 7.1), contribuyendo "a evitar el deterioro de la calidad de las masas de agua y sus sistemas asociados". 
total o relativa- de recursos económicos o impago de los precios públicos del servicio. Se comentará esta cuestión más adelante.

\section{d). Objeto: volumen de agua apta para el consumo humano}

No hay, en cualquier caso, una garantía, aún indirecta, a la disponibilidad absoluta o indefinida del recurso (incluso para exclusivos fines domiciliarios). En tanto elemento natural escaso, su entera caracterización ha de estar vertebrada sobre dos dimensiones necesariamente interrelacionadas: calidad y cantidad. La ley no ampara el uso abusivo del derecho (ni el desperdicio o mal uso de las aguas, cualquiera que fuese el título alegado, ex art. 50.4 TRLA), y los principios de ahorro, racionalización y eficiencia en el uso del agua son hoy claves para el entendimiento, a partir del marco comunitario, de la ordenación de las actividades y usos relativos a ésta. Y también desde la perspectiva "humanitaria" del mínimo vital, lo que se garantizaría sería el acceso, disponibilidad o, más concretamente, exigencia del derecho subjetivo al abastecimiento, de un volumen concreto de agua apta para el consumo humano. La cantidad mínima concreta no se fija, lógicamente en la Ley (como tampoco sucede a nivel básico, remitiéndose a estos efectos a los correspondientes instrumentos de planificación por cuenca ${ }^{61}$, pero sí resulta llamativo que no se exija la potabilidad del agua, sino sólo su aptitud para el consumo humano (condiciones que en principio podrían no coincidir) ${ }^{62}$.

Así pues, el derecho al agua o al suministro de agua (consumible) debe garantizarse en términos de una cantidad suficiente para satisfacer las necesidades básicas, según se establezca en la normativa correspondiente. En este sentido, existen ya precedentes autonómicos legales donde no sólo se reconoce la garantía del suministro de agua en cantidad y calidad adecuadas en todos los municipios (sin necesidad de

61 Desde la perspectiva sanitaria y cualitativa, sin embargo, el Real Decreto 140/2003, de 7 de febrero, por el que se establecen los criterios sanitarios de la calidad del agua de consumo humano, sí que establece que las dotaciones de agua deberán ser suficientes para las necesidades higiénico-sanitarias de la población y el desarrollo de la actividad de la zona de abastecimiento, y como objetivo mínimo debería tener 100 litros por habitante y día (art. 7.1). Parece que tanto en función del ámbito material y espacial de la previsión como de sus finalidades, la cantidad de agua como mínimo vital sería menor seguramente, aunque como veremos la D.A. $16^{\text {a }}$ LAA incluye junto al consumo y abastecimiento domiciliario también la actividad de saneamiento.

62 Para algunos autores, así, las características fundamentales del agua susceptible de ser el contenido fundamental de este derecho no serían sólo la calidad y la cantidad, sino también la "aceptabilidad", LOPERENA ROTA, D. (2007: 87). En cualquier caso, y por encima, señala el art. 5.3 LAA que la actuación administrativa en esta materia debe perseguir, necesariamente, "la protección de la salud en todos aquéllos usos destinados al ser humano, especialmente en las aguas de consumo, que implica priorizar para estos últimos el agua de mejor calidad disponible, asi como las infraestructuras para dicha finalidad'. 
proclamar un derecho específico al efecto), sino en algunos casos el porcentaje concreto del mismo ${ }^{63}$.

\section{e). Fin: atender las necesidades básicas y el saneamiento}

Finalmente, la nueva concepción autonómica del derecho al agua se caracterizaría por el elemento teleológico justificante del reconocimiento del acceso universal al recurso. La cobertura principial ampara la garantía y protección de este derecho a fin de atender, específicamente, las necesidades básicas y el saneamiento de la población. Por tanto, no hay, literalmente, una garantía exclusiva a un mínimo vital existencial, sino a un volumen mínimo de agua de consumo humano que pueda satisfacer las necesidades básicas de la persona incluyendo las de saneamiento.

\section{Sujetos}

En la indeterminación -lógica por otro lado en una previsión más declarativa que innovativa- de la Disposición que comentamos, tampoco se especifica sobre qué sujetos se proyectaría. Es evidente que si la misma incluyera, indubidatamente, un derecho subjetivo (genérico o específicamente prestacional) al agua, deberían definirse los titulares del mismo (o sujetos activos, siendo los sujetos pasivos $\mathrm{u}$ obligados, lógicamente, las Administraciones públicas responsables o titulares del servicio), mientras que si se interpreta la previsión como un mero "recordatorio" o "acogimiento normativo" de un derecho humano preexistente y previo, tal elemento, en su necesaria universalidad, devendría irrelevante. En principio, y con la duda sobre su efectiva naturaleza y funcionalidad jurídicas, habrá que interpretar la plasmación genérica del apartado primero desde la perspectiva del reconocimiento general a cualquier persona de un mínimo vital de agua de consumo. Es el sentido más lógico y racional del derecho proclamado. Todas las personas necesitan el agua para vivir. Su intrínseca necesidad justificaría la universalidad de la titularidad del derecho (aunque realmente se refiera a la atención de las necesidades básicas domiciliarias y no sólo a la pura existencia física). Aunque es verdad que los principios que dan cobertura a la declaración se refieren a la utilización solidaria del agua -que enlazaría más bien con una necesaria visión intergeneracional en su gestión, que podría legitimar entonces ciertas restricciones o limitaciones coetáneas en cuanto a su libre acceso y disponibilidad-, a la igualdad de trato -que demandaría una concreción interna normativa sobre los posibles sujetos activos de este

63 Por ejemplo, art. 19.1 de la Ley 12/2002, de 27 de junio, reguladora del Ciclo Integral del Agua de Castilla La Mancha, donde se establece que la dotación del recurso, en condiciones de normalidad, no deberá ser inferior a cien litros por habitante y día. La Ley 9/2010, de 4 de noviembre, de Aguas de Galicia, incluye también entre los principios de actuación de la Comunidad Autónoma la "garantía de la calidad del suministro del agua urbana en defensa de la salud de los ciudadanos y ciudadanas" y la "garantía de eficacia en la prestación de los servicios públicos de abastecimiento, saneamiento y depuración" (art. 3.1.e). 
derecho- y a la protección de la salud de los usuarios - ¿del servicio o del agua?-, junto con la finalidad pública de atención de las necesidades básicas de consumo doméstico de agua a un precio asequible - deber público, más que obligación estricta singular, de nuevo conectado fundamentalmente con el suministro domiciliario de agua-, lo cierto es que, en términos abstractos, la previsión lo que hace es acoger en su seno un derecho humano ya proclamado - en otras instancias, lógicamente-, desde una dimensión, en tanto mínimo vital, de garantía y protección, más que de desarrollo o concreción (normativa) estrictas. El derecho humano al agua legitimaría, entonces, el acceso universal de cualquier persona al agua, no como uso común general, ya tutelado por nuestra normativa sectorial, sino a los servicios de abastecimiento o suministro.

\section{Ejercicio del derecho: ¿transformación o realismo jurídico?}

De lo dicho anteriormente ya cabe intuir que el elemento fundamental para la dilucidación de la verdadera naturaleza normativa de este posible derecho radicaría en los instrumentos, fórmulas y marco ordenador de su ejercicio o materialización. El paso de la teoría, y de la abstracción casi ética, a la práctica, resulta, así, trascendental. Y en este sentido resulta clara la doble dimensión operativa de la nueva D.A. 16 LAA: mientras que en el primer párrafo parece acogerse, aún sin un reconocimiento directo y completo, la idea de la existencia -o preexistencia- de un auténtico derecho humano como fundamentación de las exigencias prestacionales inherentes a la teoría del mínimo vital, en el segundo párrafo, e inmediatamente, tales esperanzas se difuminan y diluyen en un "escenario" de cruda positividad (ya conocida). No es que se niegue realmente el derecho al agua, o se transforme en su concepción nuclear, sino que su concreción pasa, en el fondo, por la reconducción posibilista de sus exigencias o contenidos hacia un marco normativo realmente habilitador, desde la perspectiva estrictamente jurídica.

Dice este segundo párrafo que "las condiciones de prestación y acceso al derecho humano al agua, concebido como mínimo vital, serán objeto de desarrollo reglamentario en la disposición administrativa de carácter general que contemple las relaciones entre las entidades que prestan los distintos servicios que componen el ciclo integral del agua de uso urbano y los usuarios de los mismos".

El "salto normativo" quizás no sea decepcionante, pero sí realmente llamativo. ¿Cómo es posible que las condiciones de ejercicio, o mejor exigencia, de un derecho humano, en definitiva los parámetros de su exigibilidad y cumplimiento, se contengan en una norma reglamentaria (y sectorial autonómica)? O no estamos ante un auténtico derecho humano o la "originalidad legislativa" andaluza simplemente se 
reduciría a un revestimiento axiológico puramente nominal de la mera ordenación interna sobre la ordenación jurídica de estos servicios ${ }^{64}$.

En definitiva, el derecho humano al agua se "concretaría", a los efectos de su ejercicio efectivo, en la propia regulación positiva sobre la prestación pública de los deberes de abastecimiento. El centro de gravedad pasaría entonces desde el ciudadano (o persona), en la teoría, a los poderes públicos responsables de la ordenación y gestión de los servicios públicos sobre el agua, en la práctica. Aún desde su íntima y expresa concepción como mínimo vital, su condicionalización ordinaria matizaría enormemente la funcionalidad abstracta del derecho a estos efectos. Aun manteniendo su preexistencia, el acceso, y no tanto la exigibilidad directa, y sobre todo los requisitos de prestación, quedan remitidos, y por ello "rebajados en grado", a una futura norma reglamentaria sobre el régimen de prestación de estos servicios. ¿Qué impediría entonces -fuera del radio de acción de las respectivas "motivaciones reglamentarias"- que dicho reglamento sobre el ciclo integral del agua impusiera por ejemplo (en el caso de un cambio de gobierno -como en realidad ha sucedido en Andalucía-) condiciones o requisitos de prestación incluso más rigurosos, por ejemplo en materia tarifaria, que incluso los existentes con anterioridad, donde no estaba proclamado aparentemente el derecho al agua? El "posibilismo acompetencial" puede conducir, en el fondo, a desactivar por completo los objetivos básicos de la norma ${ }^{65}$. De nada serviría entonces una engolada proclamación o proyección autonómica de un derecho superior si en el fondo las condiciones para su ejercicio se remiten a la normativa tradicional de ordenación (local) de estos servicios públicos.

La opción normativa puede ser, en fin, la más realista (y seguramente la menos conflictiva desde el punto de vista político-territorial), pero resulta en cierta forma decepcionante. Porque al final la modulación reglamentaria viene a desactivar por completo el reconocimiento legal previo, que, a mi juicio, no supone la consagración efectiva y material de este derecho en el ordenamiento jurídico andaluz. Será el desarrollo reglamentario posterior (la garantía real de exigibilidad jurídica, aún con las evidentes limitaciones competenciales desde el punto de vista de la ordenación del recurso, hubiera demandado la previsión de una futura norma legal específica) el que, en el marco de la relación jurídica de servicio (que incluye tanto derechos como

64 Hay que señalar, sin embargo, que no nos encontramos ante una auténtica novedad en este punto. También desde la perspectiva internacional se ha podido señalar directamente que las declaraciones programáticas recaídas en los últimos tiempos se sustentan en una constatación "realista": considerar que el derecho humano al agua es en la actualidad el derecho al suministro de agua, LOPERENA ROTA, D. (2007: 90).

65 Por eso se ha apuntado que lo realmente necesario sería que "una futura reforma de la Ley de Aguas (o una nueva Ley estatal sobre el ciclo urbano del agua) reconozca expresamente este derecho y regule sus condiciones de ejercicio (cantidad, calidad, coste, modalidad de acceso)", LÓPEZ DE CASTRO GARCÍA-MORATO, L. (2018: 355) y MENÉNDEZ REXACH, Á. (2015: 201). 
obligaciones de los usuarios ${ }^{66}$ ), establezca realmente las posibilidades de acceso y disponibilidad de agua por parte de los vecinos, lo que, en el fondo, y en tanto servicio municipal obligatorio, ya estaba previsto y asegurado con anterioridad.

La viabilidad real de la nueva D. A. 16 $6^{\text {a }}$ LAA parece reducirse, pues, a la "inspiración" u "orientación" últimas de dicho futuro reglamento. Dentro de las posibilidades normativas de regulación, la voluntad del legislador parece clara: la ordenación local del servicio (es decir, las ordenanzas reguladoras que pudieran dictarse en desarrollo y aplicación de aquel) deberá priorizar la accesibilidad y asequilibilidad universales al agua, aún en el seno de las relaciones jurídicas prestacionales ${ }^{67}$. Pero este auténtico derecho subjetivo "reorientado" se fundamentaría no en la previsión legal de la LAA sino en las competencias autonómicas y su plasmación normativa sobre la prestación de determinados servicios públicos a nivel local.

Además, desde su "capacidad innovativa" de complemento y desarrollo (en el amplio margen que deja la Ley ahora en este punto), ese reglamento futuro podrá "condicionar", en más o menos realmente, el sistema o modelo de gestión urbana del agua en Andalucía. El primer párrafo de la D. A. 16 a LA sólo contiene principios generales y pautas descriptivas sobre el derecho al agua, elementos que admiten, en todo caso, un amplio margen de interpretación y concreción. Así por ejemplo, la universalidad en el acceso habrá de cohonestarse con las posibles condiciones y requisitos que se establezcan, por ejemplo según el tipo de suelo o la ubicación de las viviendas (en línea con las posibles exigencias urbanísticas sobre asentamientos urbanos), el carácter domiciliario con la necesaria concreción de lo que se entienda por vivienda, la accesibilidad con la propia ordenación de las redes e infraestructuras del servicio ${ }^{68}$, la asequibilidad, con el régimen de tarifas a satisfacer, etc.

66 Vide, así, el art. 7 LAA.

67 En este sentido parece manifestarse también, con semejante orientación, pero quizás de forma más nítida, alguna otra normativa sectorial autonómica, como la Ley 10/2014, de 27 de noviembre, de Aguas y Ríos de Aragón, cuyo art. 9 señala expresamente que "los aragoneses, en el marco del desarrollo sostenible, de la participación ciudadana, de la utilización eficaz y eficiente del recurso y de la Resolución de Naciones Unidas que define el agua como derecho humano, tienen derecho preferente a disponer de un servicio público de suministro de agua en condiciones de cantidad y calidad suficientes para satisfacer sus necesidades vitales, así como, de manera secundaria, a atender sus necesidades presentes y futuras, en el desarrollo de actividades sociales y económicas que permitan la vertebración y el reequilibrio territorial sin sobreexplotar los recursos hídricos y el medio natural ligados al mismo".

68 Cabe recordar así que la propia LAA diferencia, dentro de los usuarios del agua, a los que cabría aplicar entonces teóricamente regímenes de servicio y prestación diferentes, entre los supuestos de abastecimiento de agua por entidad suministradora, en los que sería la persona física o jurídica titular del contrato, y los casos de captaciones propias, donde sería la persona física o jurídica titular de concesión administrativa de uso de agua, autorización para el uso o titular de un derecho de aprovechamiento, y en su defecto, quien realice la captación $\left(\right.$ art. $\left.4.21^{a}\right)$. En este segundo caso, pues, no existiría realmente relación jurídica prestacional, y, entonces, ¿no habría tampoco en abstracto derecho al agua? 
Hay ya, como se sabe, precedentes autonómicos de este tipo de normas, como la Ley 12/2002, de 27 de junio, reguladora del ciclo integral del agua de Castilla La Mancha, cuyo objeto basilar es el establecimiento del marco normativo de la política de abastecimiento de agua, de saneamiento y de depuración de las aguas residuales en dicha Comunidad Autónoma, que no obstante debe atender también a finalidades que implícitamente sí que estarían conectadas no tanto con el derecho al agua pero sí con los derechos subjetivos a la exigibilidad de los servicios legalmente calificados como obligatorios, como la mejora de la asignación de recursos hídricos, mediante la diversificación y redistribución de las fuentes de suministro, la garantía de suministro de agua en cantidad y calidad adecuadas, en todos los municipios, la integración de los sistemas de abastecimiento para conseguir una gestión más eficiente, el fomento del uso racional y del ahorro del agua, la protección de las áreas de captación del recurso, etc. (art. 4.1). ¿Añade la LAA algo más? ¿Es suficiente con su recepción legal para blindar realmente, aún huérfano de contenido directo, el derecho ciudadano al agua? En mi opinión la funcionalidad del precepto es más simbólica, desiderativa o de visibilización normativa que de efectiva integración jurídica. Es evidente que, por incapacidad competencial, no podría declararse la existencia, como tal y a todos los efectos jurídicos de un derecho al agua, como derecho de acceso libre, como derecho fundamental existencial, de inspiración, base o apoyo constitucional, pero quizás pueda conducir a equívocos calificar como derecho de acceso y disponibilidad universales lo que en realidad, y por remisión, es un derecho legal a la percepción de aquéllas prestaciones públicas que sean calificadas como servicios mínimos. Con el riesgo, además, de "regresión" normativa en cuanto a su alcance en la propia -y necesaria- normativa reglamentaria de desarrollo.

\section{Derecho al agua y "pobreza hídrica"}

En este escenario de "realismo normativo", en punto a la efectiva exigibilidad de los derechos y servicios sobre el agua, resulta crucial, entre otros factores, la determinación de su "precio". Confluyen así, de nuevo, los dos vectores fundamentales para el encuadramiento genérico de un posible derecho al agua en nuestro ordenamiento: el derecho de acceso a los servicios públicos de interés general, en este caso de naturaleza económica y configuración como servicios obligatorios, y la preservación, con la recuperación de costes asociada, del recurso como dominio público. Desde ambas perspectivas - necesariamente complementarias- la "valorización" de los servicios del agua se presenta como esencial, aunque de nuevo la solución finalmente plasmada en la LAA suscita dudas e interrogantes.

Tratándose de servicios urbanos de prestación obligatoria (y sobre la base de la prelación absoluta del abastecimiento a poblaciones sobre cualquier otro uso de los recursos hídricos), el problema fundamental residirá entonces, como se ha puesto de 
manifiesto en diferentes instancias, en la garantía de efectiva accesibilidad económica por parte de los usuarios o ciudadanos en general. Como se ha calificado a nivel europeo, nos encontramos ante un auténtico "servicio social" 69 . El acceso universal, la ordenación solidaria del agua y la igualdad de trato, más allá de la efectividad y del despliegue a nivel interno de su conceptualización como auténtico derecho humano, serían incompatibles, en principio, con la imposibilidad de acceso o disponibilidad de agua para determinadas personas, grupos o zonas específicas. Tras años de crisis económica y, después, de encarecimiento en muchos casos, y por diferentes causas, de los precios del agua (y ello sin una efectiva repercusión en todos los casos de los costes ambientales), las situaciones de pobreza hídrica han sido y son, por desgracia, una realidad palpable en nuestro país. Aunque no sea, aparentemente, un problema generalizado, no puede negarse, tampoco, su existencia, y la obligación de los poderes públicos de solucionarlo, partiendo, como bien se ha dicho, de soluciones de "buena regulación"70.

No es, sin embargo, una novedad. La progresividad tarifaria, los instrumentos de bonificación o ayuda o las tradicionales fórmulas sociales de colaboración o intervención han existido con anterioridad. De hecho, el propio principio general de recuperación de costes, que demanda la incentivación del uso eficiente del agua y su integración ambiental ${ }^{71}$, ampararía el lógico establecimiento de estructuras tarifarias por tramos o bloques de consumo, permitiéndose entonces atender las necesidades básicas a un precio asequible y desincentivar los consumos excesivos, el uso inadecuado del agua o las actividades susceptibles de contaminación de los recursos y ecosistemas hídricos. Lo que se plantea ahora es, más genéricamente, la posibilidad de "inducir" de nuestro sistema constitucional la existencia de un mínimo vital al agua que "enmarque" o "fundamente" los posibles instrumentos jurídico-públicos de ordenación y asistencia (y aún más, la propia previsión genérica de un "derecho a los

69 Sobre las diferencias y características de los servicios económicos y los servicios sociales en este ámbito puede verse, por ejemplo, LAGUNA DE PAZ, J. C., "Los servicios de interés general en la Unión Europea", en Revista Derecho PUCP, núm. 76, (2016), pp. 19-50.

70 MUÑOZ MACHADO, S., "El agua en la ciudad", en El Cronista del Estado Socialy Democrático de Derecho, núm. 76, (2018), p. 5.

71 Ya el art. 9 de la Directiva marco señalaba que los Estados miembros deben de tener en cuenta el principio de la recuperación de los costes de los servicios relacionados con el agua, incluidos los costes medioambientales y los relativos a los recursos, garantizándose, a más tardar en 2010: i) que la política de precios del agua proporcione incentivos adecuados para que los usuarios utilicen de forma eficiente los recursos hídricos y, por tanto, contribuyan a los objetivos medioambientales de la Directiva y ii) una contribución adecuada de los diversos usos del agua a la recuperación de los costes de los servicios relacionados con el agua y teniendo en cuenta el principio de quien contamina paga, y al hacerlo, "los Estados miembros podrán tener en cuenta los efectos sociales, medioambientales y económicos de la recuperación y las condiciones geográficas y climáticas de la región o regiones afectadas". 
suministros básicos"72). Y en este sentido, como se avanzaba, el último párrafo de la D. A. $16^{\text {a }}$ LAA resulta claramente insuficiente, a pesar de la reconocida intención política de que el establecimiento de este mínimo vital permitiera, de forma accesible y asequible, que todos los ciudadanos y ciudadanas en Andalucía (y no sólo los vecinos en relación con los servicios locales de abastecimiento) pudieran cubrir realmente sus necesidades básicas, y que, en concreto, la regulación de los cortes de suministro por impago acogiera las situaciones de vulnerabilidad como excepciones ${ }^{73}$.

Desde la óptica sincrética a la que conduce la misma - derecho humano al agua como mínimo vital instrumentalizado como servicio público local obligatorio, en el marco mayor de la reglamentación del conjunto de servicios sobre el ciclo integral del agua de uso urbano-, y como se sabe, la cuestión quedaría remitida en principio, y a falta de normas superiores, a los correspondientes municipios, a través de las ordenanzas del servicio, que, por un lado, pueden prever "cortes" del servicio por impago de las tasas correspondientes, pero también, de otro, bonificaciones, tarifas progresivas, penalizaciones por consumo excesivo, adaptación de precios por zonas o actividades, etc. ¿Obligaría la nueva LAA a la acomodación en este punto de dichas ordenanzas del ciclo del agua?.

Sí parece evidente que, a pesar de las declaraciones políticas al respecto, la consagración del derecho en un futuro reglamento no bastaría para conformarlo como auténtico derecho subjetivo reclamable por cualquier ciudadano ${ }^{74}$. Ahora se recoge en una Ley, pero, ¿con capacidad y contenido suficientes?.

Lo que señala el último párrafo de la Disposición que comentamos es que "las personas en situación de pobreza y riesgo de exclusión social que acrediten dicha condición ante la Administración responsable de la gestión de los servicios del ciclo integral podrán ser objeto de bonificación al suministro mínimo vital de agua y al saneamiento básico, en los términos que reglamentariamente se determinen". A primera vista, de nuevo, se reproduce el reenvío o condicionamiento de un potencial derecho ciudadano a las prestaciones mínimas vitales a la normativa de gestión de los servicios urbanos del agua. Podrá denominarse así, pero en realidad la regulación positiva de habilitación no cambia. La acreditación

72 Vide así, por ejemplo, el Informe sobre el derecho a los suministros básicos (electricidad, agua y gas) del Síndic de Greuges de Catalunya, de diciembre de 2014, donde se señala que resulta "esencial superar la consideración de la persona como simple cliente de una empresa suministradora en pro de la consideración de la persona como titular de un derecho subjetivo a los suministros básicos a un precio asequible y dentro de unos parámetros de consumo básicos, esenciales o no suntuarios".

73 Documento de Conclusiones finales del proceso participativo para la elaboración del Reglamento del ciclo integral del agua de uso urbano en Andalucía, 5 de noviembre de 2018.

74 Como se ha podido decir, "dada su naturaleza, el derecho al agua ha de ser de configuración legal esencialmente. Su consagración como derecho fundamental en la Constitución no es improcedente, pero no añade mucho a las regulaciones tradicionales en España sobre el agua y el abastecimiento a poblaciones", MUÑOZ MACHADO, S. (2018: 7). 
de las situaciones de vulnerabilidad y los propios criterios determinantes del reconocimiento o no de la misma ni se prevén en la LAA ni se remiten a una normativa específica al respecto, de ámbito general, sino a la normativa específica sobre los servicios locales del agua, primando de nuevo la óptica del servicio público sobre la dimensión demanial del recurso y la exigibilidad social como mínimo vital. Se trata, pues, y paradójicamente, de una previsión de mínimos, acogiéndose además sólo, y como soluciones, la posibilidad de bonificaciones al suministro mínimo vital (existiendo otros mecanismos y fórmulas para lograr estos fines realmente).

Es verdad que, aun así, dicho reglamento puede asumir con mayor intensidad estos propósitos a través del desarrollo, complemento e integración de las situaciones de pobreza, los requisitos para la solicitud de bonificaciones o exenciones, el procedimiento a aplicar, etc., pero también que nada lo asegura, que es una norma más dependiente -y disponible- de las opciones políticas de gobierno y que, con otro simple reglamento, se podría cambiar. ¿Es entonces suficiente garantía de un derecho, más allá de su proclamación o acogimiento, su reserva legal formal? Resulta llamativa en este sentido (sobre todo porque sobre ello la Comunidad Autónoma sí podría tener más competencias) la completa falta de alusión en el precepto (repetimos, bien que "de mínimos" o de "mera proclamación") a la necesaria conexión del derecho al agua y la prevención o interdicción de las situaciones de vulnerabilidad social o personal asociadas al mismo con los modos de gestión de los servicios públicos locales. Precisamente han sido las alegaciones de la existencia de este posible derecho uno de los argumentos fundamentales en el -excesivamente polarizado a mi juicio- debate sobre la gestión directa o indirecta de los servicios públicos locales del agua, y los procesos municipales de reasunción llevados a cabo en los últimos años ${ }^{75}$. En el marco de la normativa básica estatal aplicable, el precepto se muestra neutro en este punto, con la pura remisión a la futura reglamentación de este tipo de servicios, siendo hoy más que necesario, sin embargo, remarcar que, con independencia de la forma de gestión (directa o contractual), lo importante de las Administraciones responsables es el aseguramiento del respeto de los principios generales informadores del servicio público, entre ellos, y con afección aquí, los de continuidad, universalidad, accesibilidad, transparencia e igualdad de trato $^{76}$.

75 Vide, entre otros, ALEMANY GARCÍAS, J., La recuperación de los servicios públicos locales, Civitas, Madrid, 2018; FONT i LLOVET, T. y DÍEZ SÁNCHEZ, J. J. (coords.), Los servicios públicos locales. Remunicipalización y nivel óptimo de gestión, Actas del XXI Congreso de la Asociación Ítalo-Española de profesores de Derecho Administrativo, Benidorm-Alicante, 26 a 28 de mayo de 2016, Iustel, Madrid, 2016; ESTEVE PARDO, J., "El movimiento remunicipalizador. Experiencias y expectativas", en El Cronista del Estado Social y Democrático de Derecho, núm. 69, (2017), p. 4 y ss.; etc.

76 Como se ha señalado, "en la regulación en Derecho interno del derecho humano al suministro de agua, ante la ausencia de armonización europea, cabe su articulación a través de diferentes mecanismos, según la configuración general de la actividad (liberalizada o no): así, con imposición de obligaciones de servicio público como podría ser el «servicio universal 
La solución legal andaluza es lógicamente la menos conflictiva (en su acomodación competencial), pero no seguramente la más satisfactoria, desde la perspectiva de la efectiva garantía material y tutela efectiva de las situaciones de exclusión social, incapacidad económica o vulnerabilidad, sin previsiones (ni siquiera mínimas en la Ley) sobre los sujetos afectados (¿'sólo los usuarios o cualquier ciudadano?), la forma de financiación de los gastos aparejados al reconocimiento del derecho, los mecanismos de seguimiento o control o el dato clave de los criterios o parámetros para la declaración de estas situaciones de pobreza. El reglamento podría servir para concretar el procedimiento, la documentación a aportar o los órganos competentes (uniformizando así, de paso, la variedad de soluciones, no todas igual de garantistas, contempladas en la normativa local correspondiente) $)^{77}$, pero estos elementos seguramente deberían haberse recogido en una Ley (no en la LAA sino en una sobre la gestión de los servicios sobre el agua).

En dicha norma, en fin, no sólo se debería prever el abanico de posibles medidas de intervención, bonificación o protección (en un necesario marco mayor, no obstante, de garantía de la asequibilidad del servicio sin merma del principio de recuperación de costes), dada la variedad de supuestos que pueden incluirse dentro de las situaciones genéricas de pobreza y exclusión social (más el riesgo de caer en ella ${ }^{78}$, sino la propia operatividad del importante principio de proporcionalidad, ya acogido por alguna jurisprudencia ${ }^{79}$, que debe ser atendido en el caso del ejercicio de potestades restrictivas de derechos y sancionadoras, eligiéndose el medio menos restrictivo de la libertad y seguridad personales. Como se ha dicho, el corte por impago es la medida más restrictiva y desproporcionada, especialmente en supuestos de vulnerabilidad económica ${ }^{80}$.

de suministro de aguà o el suministro a consumidores vulnerables, o incluso como servicio público reservado, y su financiación mediante diversas vías (tarifas, subvenciones, impuestos), respetando las normas europeas sobre ayudas públicas, sobre compensaciones por obligaciones de servicio público, y los principios básicos del Derecho europeo de transparencia y no discriminación", LÓPEZ DE CASTRO GARCÍA-MORATO, L. (2018: 359).

77 En el sentido del vigente Decreto 120/1991, de 11 de junio, por el que se aprueba el Reglamento del suministro domiciliario de agua, más una norma técnica sobre la gestión del servicio que garantía efectiva del suministro en el territorio andaluz.

78 En otras Comunidades Autónomas se ha puesto en conexión, así, la garantía a un mínimo dotacional de suministro de agua a domicilios con las fórmulas de protección social basadas en la "renta mínima". Sobre su configuración legal en la Comunidad andaluza puede verse MELLADO RUIZ, L., "Renta mínima de inserción e inclusión social en la Comunidad andaluza", en S. FERNÁNDEZ RAMOS y J. Ma . PÉREZ MONGUIÓ (coords.), El Derecho de los servicios sociales en Andalucía, Instituto Andaluz de Administración Pública, Sevilla, 2012, pp. 221-274, y sobre sus problemas "reales", https://www.eldiario. es/andalucia/Renta-Minima-Insercion_0_869313254.html

79 Vide MENÉNDEZ REXACH, Á. (2015: 219).

80 GIMÉNEZ CASALDUERO, M. y BABIANO AMELIBIA, L. (2013). 
Hubiera sido necesario, en definitiva, no una reforma parcial y más programática que efectiva de la Ley autonómica de Aguas, sino la aprobación definitiva de una norma legal específica reguladora de los servicios del ciclo integral del agua, a fin de dar cobertura específica a este derecho humano, aún en su concepción o "modulación" interna como derecho al suministro o abastecimiento (pero con las mismas garantías y exigencias materiales) y al conjunto de elementos y factores determinantes de su eficacia y exigibilidad, entre ellos aquéllas medidas más adecuadas, proporcionales y congruentes para hacer frente no sólo a los supuestos de pobreza, exclusión o vulnerabilidad (social, territorial, étnica, etc.), sino a las ya exigencias -y de ámbito y relevancia superior- de asunción efectiva de los principios de recuperación de los costes del agua, gestión sostenible y racional del recurso, equidad social y óptima organización y funcionamiento de los servicios (locales) correspondientes. La disponibilidad y el abastecimiento pasan en el fondo, en momentos además de incertidumbre sobre los efectos últimos del cambio climático sobre los recursos hídricos, más que por proclamaciones de derechos, por el aseguramiento de la sostenibilidad, la calidad y la asequibilidad futuras del agua ${ }^{81}$. Y la satisfacción de las demandas de los usuarios (en calidad, continuidad, regularidad, transparencia informativa, etc.), incluyendo a todas las situaciones en virtud de los principios de solidaridad, igualdad de tratamiento y asistencia mínima vital, por una ordenación adecuada de los servicios, con independencia del carácter público o privado del gestor.

\section{FINAL}

Podemos convenir en que, estrictamente hablando, la nueva D. A. 16 ${ }^{\text {a }}$ LAA no acoge y desarrolla materialmente un nuevo derecho humano, ni implementa un derecho fundamental de base expresa constitucional, sino que lo articula dentro del régimen local de prestación de los servicios mínimos obligatorios, pero también en que la intención legislativa -"suprapositiva", podría decirse- es clara y loable, seguir profundizando y dando pasos hacia la institucionalización efectiva de un derecho universal al agua potable por parte de todos los ciudadanos. Ambas perspectivas, aún en su diferente grado de expresión, deberían tenerse en cuenta a partir de ahora.

81 Como se dice en alguna norma autonómica, y como punto de partida ineludible, "el agua es un bien público y un recurso finito, vulnerable y esencial para la vida y el desarrollo humano. La gestión de los recursos hídricos, por tanto, debe basarse en la percepción del agua como un bien social y económico y una parte integral del ecosistema, cuya disponibilidad en cantidad y calidad determina la naturaleza de su uso", Preámbulo de la Ley 2/2014, de 26 de noviembre, de abastecimiento y saneamiento de aguas de la Comunidad Autónoma de Cantabria. En ella se incluye, por cierto, la garantía básica en favor de personas con menos recursos económicos de un caudal mínimo de suministro domiciliario de agua de 100 litros por habitante y día, aunque se encuentren en situación deudora del pago de los tributos vinculados al suministro (art. 16.1). 
Y en este sentido, lo que se impone sería, más allá de esta reforma puntual, la definitiva actualización y adecuación de la aún vigente normativa andaluza sobre abastecimiento a poblaciones, el conocido Decreto 120/1991, de 11 de junio, por el que se aprueba el Reglamento del Suministro Domiciliario de Agua ${ }^{82}$. Norma adecuada en su momento, pero totalmente desactualizada en la actualidad. La imbricación de las dos perspectivas reseñadas en un nuevo marco normativo (legal o reglamentario), dotando al modelo de una mayor seguridad jurídica, uniformidad y mecanismos de cumplimiento, debería traducirse, entonces, en un régimen armonizado de reestructuración de la gestión del ciclo integral urbano del agua, de tal forma que la garantía del derecho al suministro prevalezca sobre -o condicione al menoslas singularidades y excepcionalidades municipales en torno a la organización de los servicios (palpable, por ejemplo, en la diversidad de estructuras tarifarias presentes en las ordenanzas reguladoras), desde una reconsideración interna del marco competencial aplicable y una visión de coordinación y equilibrio entre la autonomía local (y las competencias de ordenación, regulación y gestión del ciclo del agua) y las responsabilidades últimas de garantía efectiva de los derechos de las autoridades regionales ${ }^{83}$.

82 Hay que recordar que la D. F. $5^{\text {a }}$ de la LAA, del año 2010, preveía la aprobación de su desarrollo reglamentario como máximo a los dos años de su entrada en vigor.

83 Estas sintéticas ideas finales se han extraído de las intervenciones en la "Jornada Divulgativa y de Participación sobre el Reglamento del Ciclo Integral del agua de uso urbano en Andalucía", celebrada en la Fundación Cajasol de Sevilla, el 11 de junio de 2018, en https://fundacioncajasol.com/jornada-el-reglamento-del-ciclo-integral-del-agua-de-uso-urbano-en-andalucia-fundacion-cajasol// 


\section{BIBLIOGRAFÍA}

AGUDO GONZÁLEZ, J. (coord.), El derecho de aguas en clave europea, La Ley, Madrid, 2010.

AGUDO GONÁLEZ, J., "La Directiva marco. La nueva cultura del agua y el imperativo de evolución de la política hidráulica española hacia un modelo de gestión sostenible", en S. GONZÁLEZ-VARAS IBÁÑEZ, Nuevo Derecho de aguas, Thomson-Civitas, Madrid, 2007.

AGUIAR RIBEIRO DO NASCIMENTO, G., "El derecho al agua y su protección en el contexto de la Corte Interamericana de Derechos Humanos", en Estudios Constitucionales, núm. 1, (2018).

ALEMANY GARCÍAS, J., La recuperación de los servicios públicos locales, Civitas, Madrid, 2018.

BELDA HÉRIZ, I., Economía circular. Un nuevo modelo de producción y consumo sostenible, Tébar, Madrid, 2018.

CAHILL, A., "The human right to water - a right of unique status: The legal status and normative content of the right to water", en International fournal of Water Resources Development, Vol. 9, núm. 3, (2006).

CALVETE MORENO, A., "El derecho humano al agua", en J. TORNOS MAS (coord.), El servicio de suministro de agua en España, Francia e Italia, Iustel, Madrid, 2018.

CARMONA CUENCA, E., "Los derechos sociales de prestación y el derecho a un mínimo vital", en Nuevas Políticas Públicas. Anuario multidisciplinar para la modernización de las Administraciones Públicas, núm. 2, (2006).

GARRO FERNÁNDEZ-VALMAYOR, J. L., "Mínimo existencial y jurisprudencia. Hacia la construcción jurisprudencial de un derecho fundamental", en E. GARCÍA DE ENTERRÍA MARTÍNEZ-GARANDE y R. ALONSO GARCÍA (coords.), Administración y justicia. Un análisis jurisprudencial. Liber amicorum Tomás-Ramón Fernández, Civitas, Madrid, 2012.

CASTILLO DAUDÍ, M., "El derecho humano al agua en el Derecho internacional: aspectos generales", en A. EMBID IRUJO (coord.), El derecho al agua, Thomson Aranzadi, Pamplona, 2006.

DELGADO PIQUERAS, F., "La irrupción del cambio climático en el Derecho europeo de aguas", en Revista Aragonesa de Administración Pública, núm. Extra 11, (2009). 
DELGADO PIQUERAS, F., "La política del agua en España: a propósito de un pacto de Estado", en F. J. JIMÉNEZ DE CISNEROS CID (dir.), Homenaje al Profesor Ángel Menéndez Rexach, Vol. II, Thomson-Reuters Aranzadi, Pamplona, 2018.

EMBID IRUJO, A., "El derecho al agua en el marco de la evolución del derecho de aguas", en A. EMBID IRUJO (coord.), El derecho al agua, Thomson-Aranzadi, Pamplona, 2006.

ESTEVE PARDO, J., "El movimiento remunicipalizador. Experiencias y expectativas", en El Cronista del Estado Social y Democrático de Derecho, núm. 69, (2017).

FONT i LLOVET, T. y DÍEZ SÁNCHEZ, J. J. (coords.), Los servicios públicos locales. Remunicipalización y nivel óptimo de gestión, Actas del XXI Congreso de la Asociación Ítalo-Española de profesores de Derecho Administrativo, Benidorm-Alicante, 26 a 28 de mayo de 2016, Iustel, 2016.

GARCÍA GARCÍA, S., "Economía circular: la Unión Europea impulsa reformas sobre la base de un tema crucial, la gestión de residuos, con el fin de alcanzar mejoras económicas y medioambientales", en Actualidad Furídica Ambiental, núm. 57, (2016).

GARCÍA RUBIO, F., "Régimen jurídico-administrativo del servicio de abastecimiento de agua a las poblaciones y sus vinculaciones urbanísticas y de servicio público", en Práctica Urbanística, núm. 120, (2013).

GIMÉNEZ CASALDUERO, M. y BABIANO AMELIBIA, L., El reconocimiento europeo del derecho humano al agua y al saneamiento: garantía ciudadana para el disfrute de los servicios públicos, en Actas del VIII Congreso Ibérico sobre Gestión y Planificación del Agua, Lisboa, 5 a 7 de diciembre de 2013, Fundación Nueva Cultura del Agua, Zaragoza, 2013.

GONZÁLEZ RÍOS, I., "Incidencia del cambio climático en los recursos hídricos. Medidas de mitigación y adaptación", en Revista Aragonesa de Administración Pública, núm. Extraordinario, núm. 11, (2009).

LAGUNA DE PAZ, J. C., "Los servicios de interés general en la Unión Europea”, en Revista Derecho PUCP, núm. 76, (2016).

LOPERENA ROTA, D., "El agua como derecho humano", en S. GONZÁLEZ-VARAS IBÁÑEZ, Nuevo Derecho de aguas, Thomson-Civitas, Pamplona, 2007.

LÓPEZ DE CASTRO GARCÍA-MORATO, L., "Sobre el derecho al agua a un precio asequible y sostenible", en F. J. JIMÉNEZ DE CISNEROS CID (coord.), Homenaje al Profesor Ángel Menéndez Rexach, Vol. I, Thomson Reuters-Aranzadi, Pamplona, 2018. 
LOTHAR, M., “¿El contenido esencial como común denominador de los derechos fundamentales en Europa?", en Revista de Derecho Constitucional Europeo, núm. 11, (2009).

MELLADO RUIZ, L., Aguas y ordenación del territorio en el contexto de la reforma estatutaria, Comares, Granada, 2010.

MELLADO RUIZ, L., "Renta mínima de inserción e inclusión social en la Comunidad andaluza”, en S. FERNÁNDEZ RAMOS y J. Mª PÉREZ MONGUIÓ (coords.), El Derecho de los servicios sociales en Andalucía, Instituto Andaluz de Administración Pública, Sevilla, 2012.

MENÉNDEZ REXACH, Á., "El derecho al agua en la legislación española", en F. LÓPEZ MENUDO, (coord.), Derechos y garantías del ciudadano. Estudios en homenaje al Profesor Alfonso Pérez Moreno, Iustel, Madrid, 2012.

MENÉNDEZ REXACH, Á., "El derecho al agua en España”, en Revista Europea de Derechos Fundamentales, núm. 25, (2015).

MILANS DEL BOSCH Y JORDÁN DE URRIES, S., "El derecho humano al agua y a la seguridad jurídica en el sector y en los consumidores (caso Ter-Llobregat)", en https://www.cuatrecasas.com/es/publicaciones/el_derecho_humano_al_ agua y a la seguridad juridica en el sector.html

MITRE GUERRA, E. J., El derecho al agua. Naturaleza jurídica y protección legal en los ámbitos nacionales e internacional, Iustel, Madrid, 2012.

MITRE GUERRA, E., "La protección del derecho al agua en el derecho constitucional comparado y su introducción en los criterios de tribunales internacionales de derechos humanos", en Pensamiento jurídico, núm. 35, (2012).

MONTORO CHINER, M.J., "Agua, Derecho y cambio climático”, en Revista Aragonesa de Administración Pública, núm. Extra 11, (2009).

MUÑOZ MACHADO, S., "El agua en la ciudad", en El Cronista del Estado Social y Democrático de Derecho, núm. 76, (2018).

NOGUEIRA LÓPEZ, A. y ARIAS MARTÍNEZ, M. A., "Blindar el Estado social: una mejora regulatoria para un tiempo de crisis", en VV. AA., Estructuras administrativas y racionalización del gasto público. Problemas actuales de la expropiación forzosa. La reforma de los entes locales en Italia en el contexto de la crisis económica. Actas del VII Congreso de la Asociación Española de Profesores de Derecho Administrativo, Tarragona, 10 y 11 de febrero de 2012, INAP, Madrid, 2012.

ORTÍZ DE TENA, M. G., "La protección de la calidad de las aguas", en $R e^{-}$ vista Andaluza de Administración Pública, núm. 71-72, (2008). 
PAREJO ALFONSO, L., "El contenido esencial de los derechos fundamentales en la jurisprudencia constitucional: a propósito de la Sentencia del Tribunal Constitucional de 8 de abril de 1981", en Revista Española de Derecho Constitucional, núm. 3, (1981).

PAREJO ALFONSO, L., "Cambio climático, riesgo global, innovación y Derecho", en L. PAREJO ALFONSO, El Derecho ante la innovación y los riesgos derivados del cambio climático, Tirant lo Blanch, Valencia, 2015.

PIÑAR MAÑAS, J. L. (coord.), Crisis económica y crisis del Estado de bienestar. El papel del Derecho Administrativo, Reus, Madrid.

PONCE SOLÉ, J., "El Estado social y democrático de Derecho ante la austeridad y los recortes sociales: la jurisprudencia del Tribunal Constitucional y su interés para el caso español”, en Revista de Derecho Constitucional Europeo, núm. 23, (2015).

PONCE SOLÉ, J., El derecho y la (ir)reversibilidad limitada de los derechos sociales de los ciudadanos: las líneas rojas constitucionales a los recortes y la sostenibilidad social, Instituto Nacional de Administración Pública, Madrid, 2013.

REGO BLANCO, M. D., La acción popular en el Derecho administrativo, y, en especial, en el urbanistico, Instituto Andaluz de Administración Pública, Sevilla, 2005.

RODRÍGUEZ ÁLVAREZ, A., "El derecho al agua en el contexto internacional y en el ordenamiento jurídico interno español", en Revista de Derecho, Agua y Sostenibilidad (REDAS), núm. 2, (2018).

RODRÍGUEZ-ARANA MUÑOZ, J., "Dimensiones del Estado social y derechos fundamentales sociales", en Revista de Investigaciones Constitucionales, Vol. 2, núm. 2, (2015).

TARRÉS VIVES, M., "La calidad del agua como concepto jurídico”, en M.J. MONTORO CHINER (coord.), El agua: estudios interdisciplinares, Atelier, Barcelona, 2009.

TORTAJADA, G., "Water as a human right", en International fournal of Water Resources Development, Vol. 33, núm. 4, (2017).

VAQUER GABALLERÍA, M., "Derecho a la vivienda y garantía de un mínimo vital: algunas propuestas", en El Cronista del Estado Socialy Democrático de Derecho, núm. 48, (2014).

VAQUER CABALLERÍA, M., "Retos y oportunidades para una política cabal de vivienda tras la crisis económica”, en T. DE LA QUADRA-SALCEDO FERNÁNDEZ DEL CASTILLO, Los servicios públicos tras la crisis económica. En especial la asistencia sanitaria en la Unión Europea, Tirant lo Blanch, Valencia, 2017. 